\title{
A form of perforant path LTP can occur without ERK1/2 phosphorylation or immediate early gene induction
}

\author{
Oswald Steward, ${ }^{1,2,4}$ Fen Huang, ${ }^{1}$ and John F. Guzowski ${ }^{2,3}$ \\ ${ }^{1}$ Reeve-Irvine Research Center, Departments of Anatomy and Neurobiology, Neurobiology and Behavior, and Neurosurgery, \\ University of California at Irvine, Irvine, California 92697, USA; ${ }^{2}$ Center for the Neurobiology of Learning and Memory, University \\ of California at Irvine, Irvine, California 92697, USA; ${ }^{3}$ Department of Neurobiology and Behavior, University of California at \\ Irvine, Irvine, California 92697, USA
}

\begin{abstract}
Stimulation paradigms that induce perforant path long-term potentiation (LTP) initiate phosphorylation of ERK1/2 and induce expression of a variety of immediate early genes (IEGs). These events are thought to be critical components of the mechanism for establishing the changes in synaptic efficacy that endure for hours or longer. Here we show that in mice, perforant path LTP can be induced using a standard protocol (repeated trains at $250 \mathrm{~Hz}$ ), without accompanying increases in immunostaining for p-ERK1/2 or increased in expression of representative IEGs (Arc and c-fos). Signaling pathways capable of inducing ERK phosphorylation and IEG transcription are intact in mice because ERK phosphorylation differs strikingly in awake versus anesthetized mice, and IEG expression is strongly induced by electroconvulsive seizures. In pursuing the reasons for the lack of induction with LTP, we found that in rats, one of the stimulation paradigms used to induce perforant path LTP (trains at $250 \mathrm{~Hz}$ ) also does not activate MAP kinase or induce IEG expression, despite the fact that the LTP induced by $250 \mathrm{~Hz}$ stimulation requires NMDA receptor activation and persists for hours. These findings indicate that there are different forms of perforant path LTP, one of which does not require MAP kinase activation or IEG induction. Moreover, these data demonstrate that different LTP induction paradigms do not have identical molecular consequences, which may account for certain discrepancies between previous studies.
\end{abstract}

Long-term potentiation (LTP) was first discovered in studies involving the perforant path projections from the medial entorhinal cortex to the dentate gyrus in vivo (the medial perforant path) (Bliss and Lomo 1973). Since this initial discovery, LTP-like phenomena have been discovered in many different CNS pathways. Although brain slices and cells in culture have provided critical insights into cellular mechanisms and molecular correlates of LTP, studies involving the perforant path have continued to provide critical information about LTP in vivo.

Perforant path LTP is triggered by high-frequency synaptic activation that is sufficient to activate NMDA receptors, triggering $\mathrm{Ca}^{2+}$ influx. Increases in synaptic efficacy are seen within seconds after a high-frequency train, and when a sufficient number of trains are delivered, the resulting increases in synaptic efficacy persist for hours to days. Although different groups use different stimulation paradigms to induce LTP in the perforant path, there has been a tacit assumption that different patterns of activation, if sufficiently strong, all engage the same basic mechanism (at least there have been no reports to the contrary).

The early phase of LTP is thought to be mediated by activation of various kinases, including calcium-calmodulindependent kinase II (CAMKII), protein kinase C, and MAP kinase. Different kinase pathways may play different roles in the lateral versus medial subdivisions of the perforant path, in that blockade of CAMKII prevents LTP in the lateral perforant path, but causes only small decrements in LTP in the medial perforant path (Zhang et al. 2005). Molecular/structural correlates of the early phase of LTP in the medial perforant path include polymeriza-

\footnotetext{
${ }^{4}$ Corresponding author.
}

E-mail osteward@uci.edu; fax (949) 824-2625.

Article is online at http://www.learnmem.org/cgi/doi/10.1101//m.554607. tion of actin in the activated dendritic lamina (Fukazawa et al. 2003), alterations in spine size and shape (Desmond and Levy 1983), and changes in psd length (Desmond and Levy 1986, 1988).

The distinguishing feature of the late phase of LTP that persists after 3-4 h (L-LTP) is that it is blocked by inhibitors of protein synthesis (Krug et al. 1984; Otani et al. 1989; Fukazawa et al. 2003), suggesting that protein synthesis is required to create or maintain enduring synaptic changes. Stimulation paradigms that induce perforant path L-LTP also strongly induce the expression of immediate early genes (IEGs) including c-fos (Cole et al. 1989), Zif268, Arc (Lyford et al. 1995), Homer (Brakeman et al. 1997; French et al. 2001), and BDNF (Castren et al. 1993). Other evidence suggests that induction of IEG expression that accompanies LTP is critical to L-LTP and memory (Guzowski et al. 2000; Jones et al. 2001b). These data indicate that IEGs are among the proteins that must be made for L-LTP to occur, but synthesis of other proteins may also be required.

Signal-transduction pathways capable of mediating gene induction associated with L-LTP have been identified. For example, high-frequency stimulation of the medial perforant path strongly activates the MAP kinase pathway, as evidenced by dramatic phosphorylation of extracellular regulated kinase (ERK) $1 / 2$ and translocation of phosphorylated ERK to the nucleus (Davis et al. 2000). In addition, it has been shown that local injection of a MEK inhibitor into the hippocampus blocked IEG induction and attenuated perforant path LTP (Rosenblum et al. 2002). Together, these results suggest that perforant path LTP involves (1) repeated intense synaptic activation that engages NMDA receptors and triggers $\mathrm{Ca}^{2}$ influx; (2) activation of kinase cascades that trigger the initial increase in synaptic efficacy; (3) phosphorylation of ERK1/2 and translocation of p-ERK into the 
nucleus; and (4) activation of gene expression, including IEG transcription factors capable of activating secondary response genes, and IEG "effectors" capable of modulating synaptic function (like activity-regulated cytoskeletal [Arc] protein).

Given this background, we were surprised to discover that in mice the stimulation paradigms used to induce perforant path LTP in rats did induce long-lasting synaptic potentiation, but did not reliably activate MAP kinase, as measured by phosphorylation of ERK1/2 or reliably induce IEG expression in dentate granule cells. In pursuing the possible reasons for this dissociation, we then found that in rats one of the stimulation paradigms used to induce perforant path LTP (trains at $250 \mathrm{~Hz}$ ) also did not activate MAP kinase or induce IEG expression, despite the fact that the LTP induced by $250 \mathrm{~Hz}$ stimulation requires NMDA receptor activation, and persists for hours. Together, these results indicate that there are different forms of perforant path LTP that are activated by different stimulation paradigms, and that one form of perforant path LTP can occur without triggering ERK1/2 phosphorylation or IEG induction.

\section{Results}

Most studies of perforant path LTP involve the "medial perforant path," which terminates in the middle molecular layer of the dentate gyrus on dentate granule cells (Steward 1976). A commonly used paradigm to induce LTP involves delivery of brief (four- to eight-pulse) trains at $400 \mathrm{~Hz}$; for example, our standard paradigm involves the delivery of a total of 30 trains, with each set of 10 trains being separated by a testing period in which 10 test responses are collected. The LTP induced in this way is highly reliable and long lasting. Indeed, in 39 experiments carried out over a 3-yr period, in which we recorded the positive response at the granule cell body layer, early LTP was induced in every case (mean increase in EPSP slope-39 $\pm 14 \%$; mean increase in population-spike amplitude-245 $\pm 117 \%)$.

\section{Level of ERK1/ 2 phosphorylation prior to stimulation}

ERK1/2 phosphorylation is regulated by synaptic activity, and thus the pattern of immunostaining depends on whether or not animals have been anesthetized for a prolonged period immediately prior to death. Immunostaining of sections from rats that have been taken from their home cage during the light cycle and killed immediately reveals a laminated pattern of staining in the hippocampus that corresponds to the distribution of different afferent systems (Fig. 1A,B). In the hippocampus proper, the highest level of staining is in stratum radiatum and oriens (the site of termination of the commissural/associational system) with a sharp boundary at the border with stratum lacunosummoleculare (the site of termination of projections from the entorhinal cortex). A laminated pattern is also seen in the dentate gyrus (Fig. 1B), with relatively high levels of staining in the inner molecular layer (the site of termination of the commissural/ associational system), low levels of staining in the middle molecular layer (the site of termination of the medial perforant path), and somewhat higher levels of staining in the outer molecular layer (the site of termination of the lateral perforant path). It is noteworthy that the boundaries between certain layers are sharply defined and seem to correspond precisely with the boundaries between the terminal fields of different afferent systems (especially the boundary between the terminal field of the commissural/associational system and the projections from the entorhinal cortex). In addition, individual neurons with even higher levels of labeling can be seen scattered throughout the hippocampus and dentate gyrus (Fig. 1B, arrows). Neurons with high levels of p-ERK staining can also be seen in other brain regions, including the cerebral cortex (Fig. 1C).
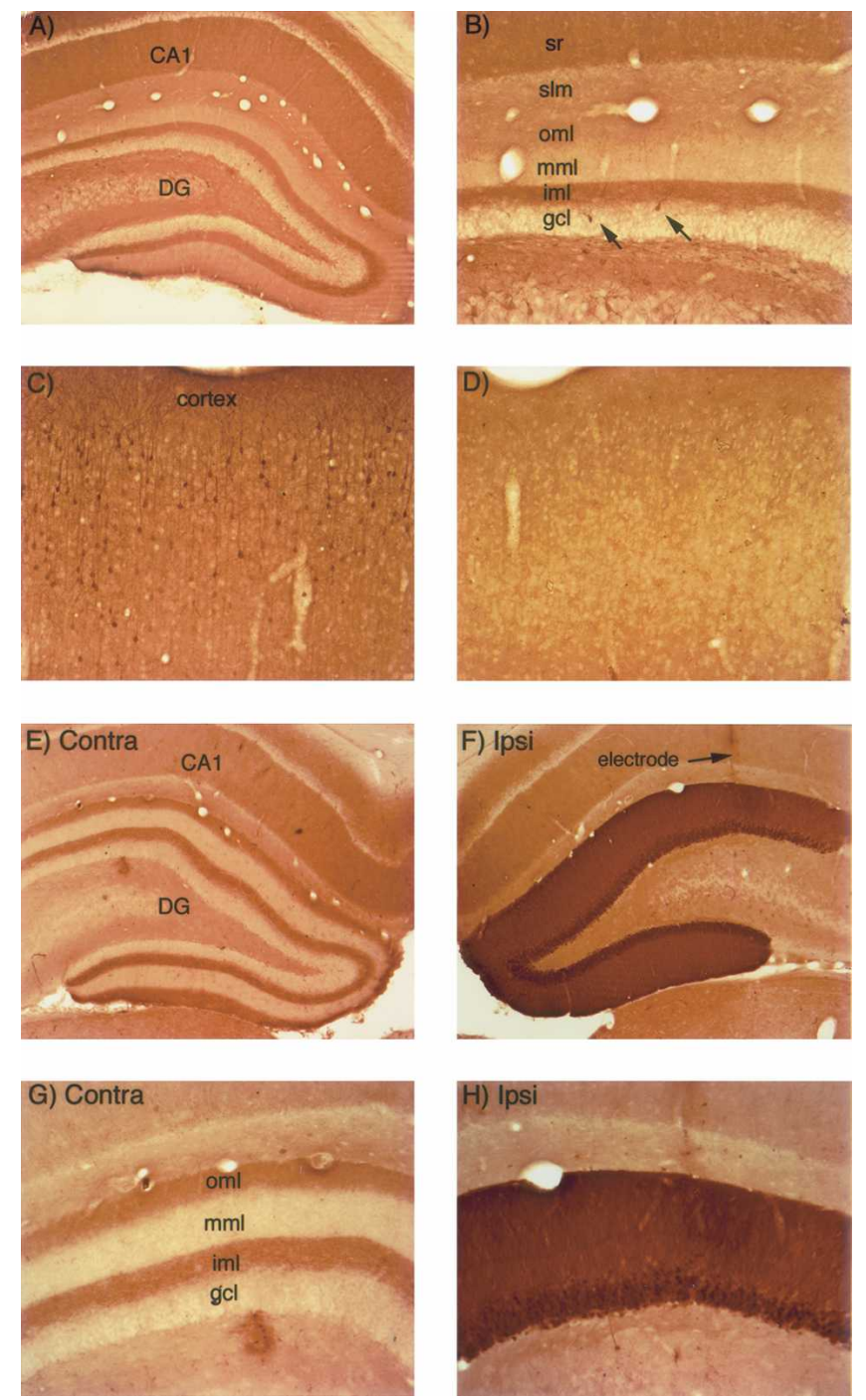

Figure 1. Activity-dependent regulation of ERK $1 / 2$ phosphorylation in rats. $(A, B)$ pattern of immunostaining for $p$-ERK in the hippocampus in a rat that was perfused immediately after receiving a fatal anesthetic dose (that is, the rat was awake until $\sim 3$ min before perfusion). (C) Pattern of immunostaining for $\mathrm{p}$-ERK in the cerebral cortex of the rat illustrated in $A$ and $B$. Note heavily stained individual neurons. $(D)$ Pattern of immunostaining for $p$-ERK in the cerebral cortex of a rat that had been anesthetized for $\sim 2.5 \mathrm{~h}$ during a neurophysiological experiment. (E) Pattern of immunostaining on the control (nonstimulated) side of the hippocampus of a rat that had been anesthetized for $\sim 2.5 \mathrm{~h}$ during a neurophysiological experiment. $(F)$ Induction of ERK1/2 phosphorylation following induction of LTP using $400 \mathrm{~Hz}$ stimulation. The track of the micropipette recording electrode is indicated. $(G, H)$ Higher magnification views of the dorsal blade of the dentate gyrus from the sections illustrated in $E$ and $F$. Note the laminar pattern of staining for $p$-ERK in the molecular layer of the control dentate gyrus and the dramatic increase in immunostaining on the stimulated side. $\mathrm{CA} 1=\mathrm{CA} 1$ region of the hippocampus; (DG) dentate gyrus; (sr) stratum radiatum; (iml) inner molecular; $(\mathrm{mml})$ middle molecular layer; (oml) outer molecular layer; and (slm) stratum lacunosum-moleculare.

The pattern of immunostaining is different in animals that have been anesthetized for some time ( $1-2 \mathrm{~h}$ ), in that there are fewer individual neurons exhibiting high levels of p-ERK staining (see, e.g., Fig. 1D, which illustrates the same region of the cerebral cortex illustrated in Fig. 1C). This suggests that the level of phosphorylation of ERK1/2 in individual neurons is determined by the level of ongoing synaptic activity, which would be lower in

\section{Learning \& Memory}


anesthetized animals. The laminated pattern of immunostaining is still seen in the hippocampus, but there are few, if any, individual neurons with high levels of staining (see, e.g., the side contralateral to the stimulation in Fig. 1E,G).

In rats, the induction of perforant path LTP by $400 \mathrm{~Hz}$ stimulation triggers rapid ERK1/ 2 phosphorylation in dentate granule cells

Induction of LTP using $400 \mathrm{~Hz}$ stimulation triggers robust increases in immunostaining for p-ERK1/2 in dentate granule cells. For example, Figure 1F illustrates striking increases in p-ERK immunostaining in an experiment in which three rounds of 10400 $\mathrm{Hz}$ trains were delivered, each of which was followed by 10 test pulses in order to assess the extent of LTP after each round of stimulation (a total of 30 trains and 30 test pulses). Trains and test stimulation were delivered at $1 / 10$-sec intervals, so that the entire induction protocol required $10 \mathrm{~min}$. The rat was perfused $\sim 2$ min after the end of the third test period, which was $\sim 4$ min after the last high-frequency train. Increases in immunostaining for p-ERK occurred throughout the dendritic and cell body layers, not just at the region of the activated synapses. Hence, the signal at the synapse triggers rapid ERK phosphorylation throughout the postsynaptic cell, which could provide a mechanism for rapid signaling between synapses on dendrites and the neuronal cell body.

In rats, the induction of perforant-path LTP by $400 \mathrm{~Hz}$ stimulation induces IEG expression

Consistent with previous studies (Cole et al. 1989; French et al. 2001; Waltereit et al. 2001), induction of perforant path LTP using $400 \mathrm{~Hz}$ trains strongly induced the expression of IEGs, including c-fos and Arc. Transcriptional activation (increases in mRNAs for IEGs) was evident within minutes (see below), and increases in IEG protein levels were evident by $30 \mathrm{~min}$ poststimulation. For example, Figure 2 illustrates the induction of c-fos protein in dentate granule cells $30 \mathrm{~min}$ after inducing LTP by delivering 30 eight-pulse trains at $400 \mathrm{~Hz}$ as in the case illustrated in Figure 1. Although $30 \mathrm{~min}$ is relatively early in the induction period, and thus levels of immunostaining for IEG proteins have not yet reached their peak, it is clear that c-fos protein expression has been induced in the vast majority of dentate granule cells.

In our previous studies of signals that lead to the targeting of Arc mRNA and protein to active synapses (Steward and Worley 2001), we have found it useful to stimulate for longer time periods than are necessary to elicit LTP in order to maximize the IEG response. For example, delivery of trains every $10 \mathrm{sec}$ for $1-2 \mathrm{~h}$ strongly induces IEG expression and also induces a selective localization of Arc mRNA in the activated dendritic lamina, which serves as a reporter for the signals that lead to the targeting of Arc mRNA and protein to active synapses. For example, Figure 2, C-F, illustrate the strong induction of c-fos and Arc protein expression in dentate granule cells after delivering $400 \mathrm{~Hz}$ trains at a rate of $1 / 10 \mathrm{sec}$ for $2 \mathrm{~h}$. Also evident is a striking band of newly synthesized Arc protein in the middle molecular layer (Fig. 2F, arrows), where the synapses of the medial perforant path terminate. ERK1/2 phosphorylation is also maintained when stimulation is delivered for $1-2 \mathrm{~h}$ (Fig. $2 \mathrm{G}-\mathrm{H}$ ), and there is a sharply defined band of increased immunostaining for p-ERK in the middle molecular layer in the location of the activated synapses (Fig. $2 \mathrm{H}$, arrows).

\section{The optimal stimulation paradigms for inducing} perforant-path LTP are different in mice versus rats In our initial attempts to induce the molecular changes described above in mice, we found that the $400 \mathrm{~Hz}$ stimulation paradigm
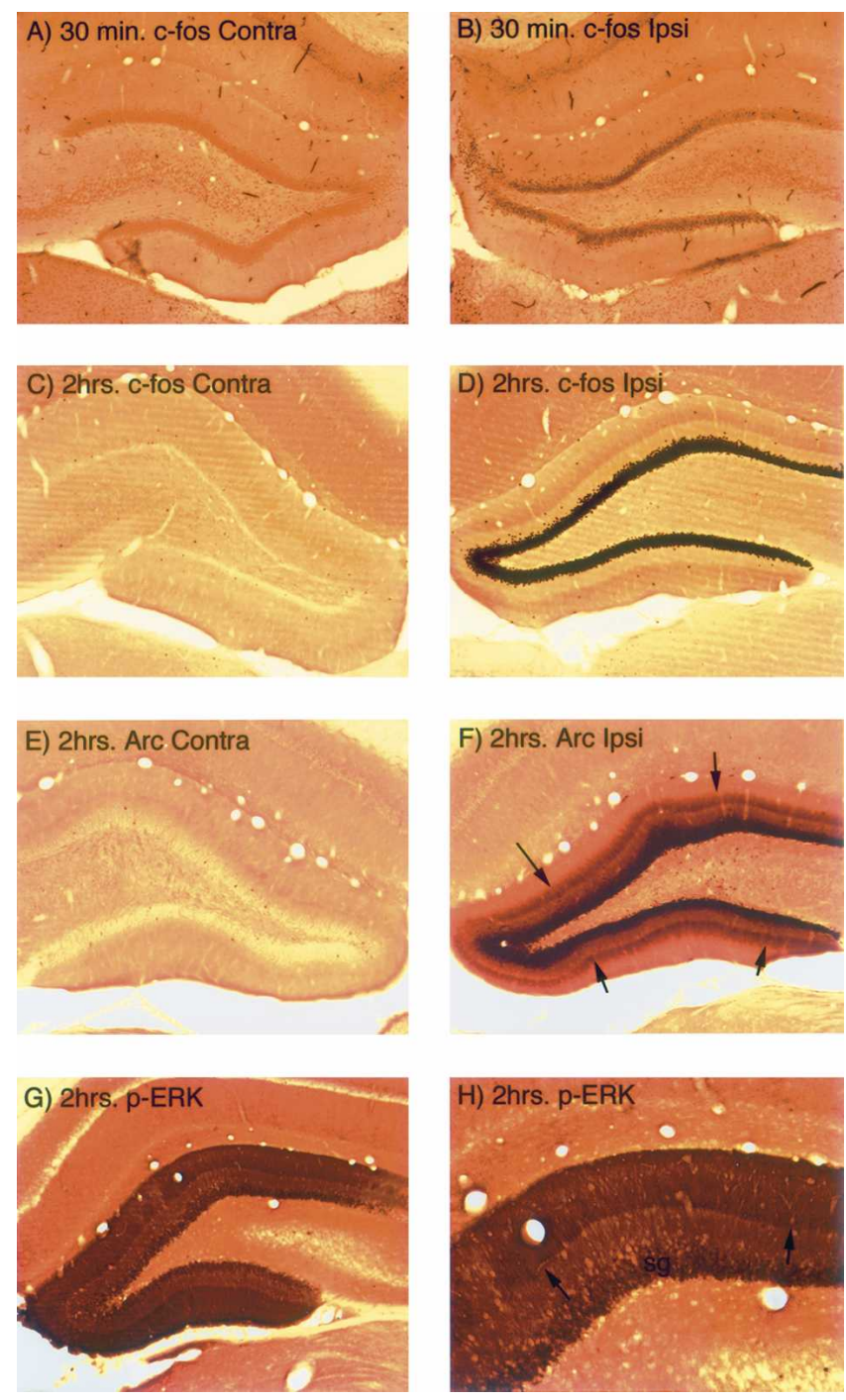

Figure 2. Increases in IEG expression following induction of LTP using $400 \mathrm{~Hz}$ stimulation in rats. (A) Immunostaining for c-fos on the control (nonstimulated) side of the hippocampus of a rat that had been anesthetized for $\sim 1 \mathrm{~h}$ during a neurophysiological experiment. (B) Increases in immunostaining for $\mathrm{c}$-fos in dentate granule cells following induction of LTP using $400 \mathrm{~Hz}$ stimulation in rats. (C) Immunostaining for c-fos on the control (nonstimulated) side of the hippocampus of a rat that had been anesthetized for $\sim 2.5 \mathrm{~h}$ during a neurophysiological experiment. $(D)$ Increases in immunostaining for c-fos in dentate granule cells following delivery of $400 \mathrm{~Hz}$ trains every $10 \mathrm{sec}$ for $2 \mathrm{~h}$. (E) Immunostaining for Arc on the control (nonstimulated) side of the hippocampus of a rat that had been anesthetized for $\sim 2.5 \mathrm{~h}$ during a neurophysiological experiment. $(F)$ Increases in immunostaining for Arc in dentate granule cells following delivery of $400 \mathrm{~Hz}$ trains every $10 \mathrm{sec}$ for $2 \mathrm{~h}$. Note band of increased immunostaining in the middle molecular layer (the site of termination of the synapses that were activated). $(G, H)$ Low- and highmagnification views of the increases in immunostaining for $p$-ERK in the dentate gyrus following delivery of $400 \mathrm{~Hz}$ trains every $10 \mathrm{sec}$ for $1 \mathrm{~h}$ Note band of increased immunostaining in the middle molecular layer (the site of termination of the synapses that were activated).

that we typically use in rats did induce LTP in some mice, but that LTP was not reliably seen. For example, Figure 3A illustrates an experiment in which the recording electrode was positioned in the molecular layer of the dentate gyrus so as to record the negative-going population EPSP. In this experiment, the stimulus intensity was set at a high level so as to elicit an $8 \mathrm{mV}$ population spike, although this was still below the maximal amplitude that 
A

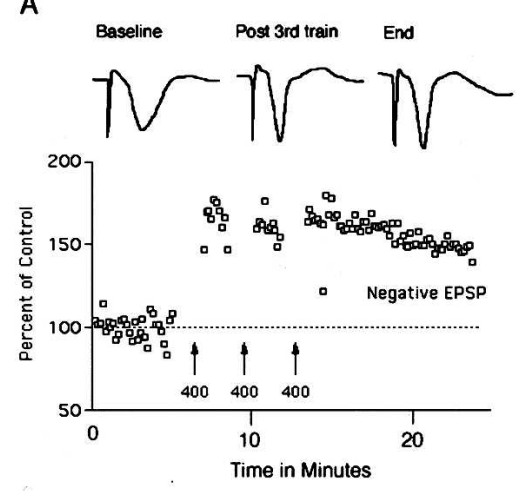

B

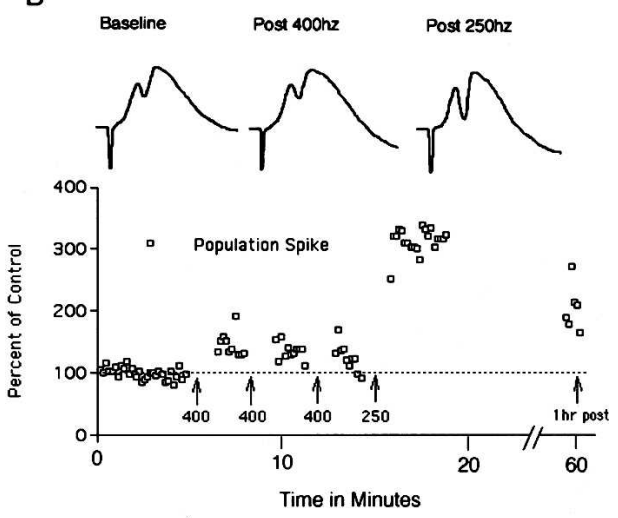

C

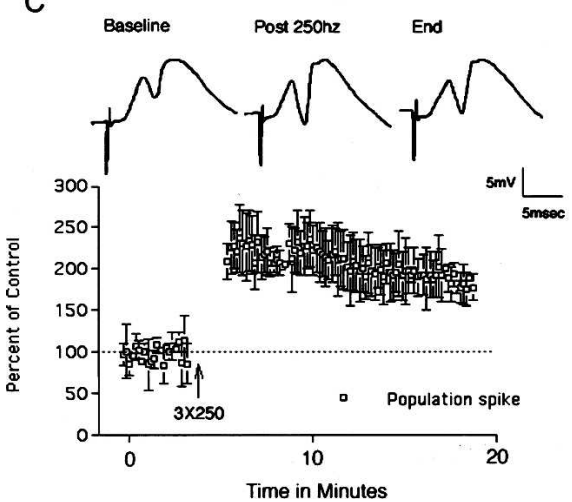

Figure 3. Perforant path LTP in mice. (A) Perforant path LTP induced by $400 \mathrm{~Hz}$ stimulation. Traces illustrate negative-going population EPSPs recorded by a micropipette positioned in the molecular layer of the dorsal blade of the dentate gyrus. The graph illustrates EPSP amplitude as a percent of baseline before and after $400 \mathrm{~Hz}$ stimulation. (B) Perforant path LTP is induced more readily by $250 \mathrm{~Hz}$ than $400 \mathrm{~Hz}$ stimulation. In this experiment, three bouts of $400 \mathrm{~Hz}$ stimulation did not induce LTP, whereas three bouts of $250 \mathrm{~Hz}$ stimulation at the same intensity was effective in inducing LTP. Traces illustrate positive-going population EPSPs and population spikes recorded by a micropipette positioned in the cell body layer of the dorsal blade of the dentate gyrus. The graph illustrates population-spike amplitude as a percent of baseline before and after $400 \mathrm{~Hz}$ and then $250 \mathrm{~Hz}$ stimulation. Data points on the far right indicate population-spike amplitude $1 \mathrm{~h}$ after inducing LTP with $250 \mathrm{~Hz}$ stimulation. (C) Average LTP induced by $250 \mathrm{~Hz}$ stimulation in three experiments. The graph illustrates the average population-spike amplitude as a percent of baseline \pm SD. Traces illustrate positive-going population EPSPs and population spikes recorded by a micropipette positioned in the cell body layer of the dorsal blade of the dentate gyrus in a representative animal. could be induced with higher intensity stimulation. Delivery of three bouts of $10400 \mathrm{~Hz}$ trains at this intensity induced robust EPSP potentiation. This experiment was exceptional, however. Overall, in the experiments in which we attempted to induce LTP in mice using $400 \mathrm{~Hz}$ stimulation alone, potentiation was induced in seven/20 experiments using intensities that elicited population spikes ranging from $2-8 \mathrm{mV}$. This is in contrast to rats, where the threshold intensity for inducing LTP with $400 \mathrm{~Hz}$ stimulation is just above threshold for inducing a population spike (Douglas 1977), and LTP occurs with a high degree of reliability (39 of 39 experiments over the past $3 \mathrm{yr}$ ).

Different laboratories use different stimulation paradigms to induce perforant path LTP in rats, the most common being repeated short (eight- to 10-pulse) trains at $400 \mathrm{~Hz}$ as described above, longer (1 sec) trains at $400 \mathrm{~Hz}$ (Fukazawa et al. 2003), or several 50-pulse trains at $250 \mathrm{~Hz}$. In our studies in rats, 400 and $250 \mathrm{~Hz}$ stimulation paradigms appear to be equally effective (see below). Accordingly, we tried the $250 \mathrm{~Hz}$ paradigm in mice, and found that it was more reliable in inducing LTP than the $400 \mathrm{~Hz}$ stimulation paradigm. For example, in five of the 17 experiments noted above in which $400 \mathrm{~Hz}$ stimulation did not induce LTP, we subsequently delivered $250 \mathrm{~Hz}$ stimulation. In all five of these experiments, $250 \mathrm{~Hz}$ stimulation induced LTP of the population spike after $400 \mathrm{~Hz}$ stimulation at the same intensity had been ineffective. A representative experiment is illustrated in Figure $3 \mathrm{~B}$.

It should be noted that in mice, it is difficult to obtain reliable measures of EPSP slope, especially over long periods of time. Part of the problem is that the dipole formed by the collection of granule cells is smaller than in rats. Thus, the recording electrode must be precisely positioned to optimally record the population EPSP and very small (20-40 $\mu \mathrm{m})$ movements can cause substantial changes in EPSP slope. Also, in mice the positive-going EPSP is often relatively flat before the onset of the population spike, especially when large population spikes are evoked. Moreover, in many experiments the slope of the positive-going population EPSP decreased over time; this occurred in the absence of highfrequency stimulation. These facts make long-term recording of the population EPSP difficult in mice. The traces of Figure 3B illustrate an experiment in which there was clear potentiation of the positive going EPSP early on (EPSP slope increased $24 \%$ over the baseline following $250 \mathrm{~Hz}$ stimulation), but this was also an experiment in which the EPSP slope decreased slowly over time, so that it was not possible to determine whether stable EPSP potentiation had occurred. For these reasons, our determinations of the presence or absence of LTP are based on the populationspike measures.

The average population-spike LTP induced by $250 \mathrm{~Hz}$ stimulation in three mice is illustrated in Figure 3C. Overall, in experiments in which $250 \mathrm{~Hz}$ stimulation was delivered first, population-spike LTP was induced in seven/10 experiments. Overall, in the experiments in which $250 \mathrm{~Hz}$ stimulation was used (either alone or after $400 \mathrm{~Hz}$ stimulation), LTP was successfully induced in $12 / 15$ experiments.

\section{In mice, perforant path LTP can occur without MAP kinase activation or IEG induction}

The overall pattern of immunostaining for p-ERK in mice was similar to what is seen in rats. When mice were removed from their home cage during the light cycle and killed immediately, individual neurons exhibiting high levels of immunostaining were present throughout the brain (Fig. 4A-C illustrate the hippocampus, dentate gyrus, and cerebral cortex, respectively). There was also a laminated pattern of staining in the hippocampus that was similar to what is seen in rats (cf. Figs. 4A and 1A), 

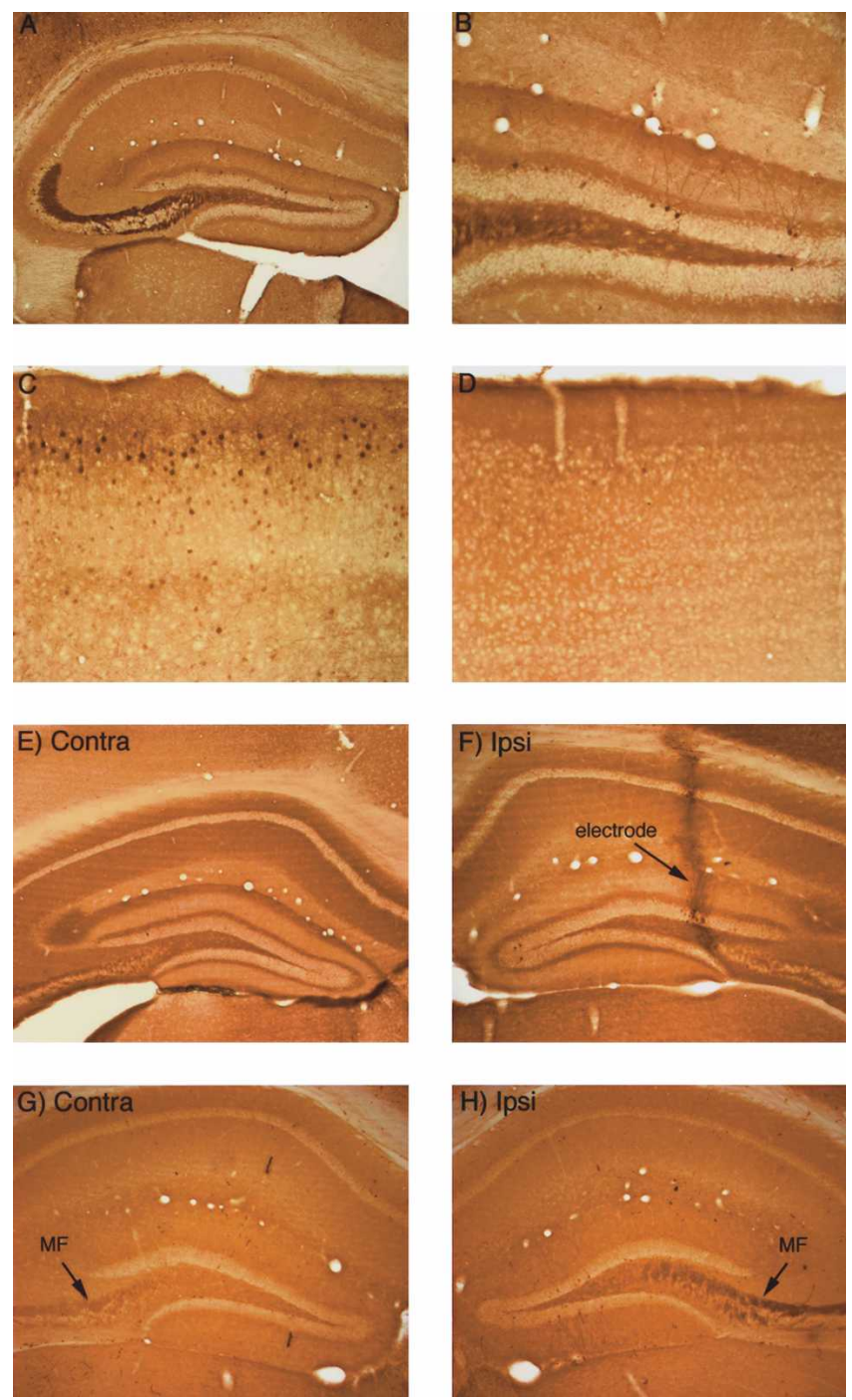

Figure 4. Activity-dependent regulation of ERK $1 / 2$ phosphorylation in mice. $(A, B)$ Pattern of immunostaining for $\mathrm{p}$-ERK in the hippocampus in a mouse that was perfused immediately after receiving a fatal anesthetic dose (that is, the mouse was awake until $\sim 3$ min before perfusion). (C) Pattern of immunostaining for $\mathrm{p}$-ERK in the cerebral cortex of the mouse illustrated in $A$ and $B$. Note heavily stained individual neurons. (D) Pattern of immunostaining for $p$-ERK in the cerebral cortex of a mouse that had been anesthetized for $\sim 2.5 \mathrm{~h}$ during a neurophysiological experiment. (E) Pattern of immunostaining on the control (nonstimulated) side of the hippocampus of a mouse that had been anesthetized for $\sim 2.5 \mathrm{~h}$ during a neurophysiological experiment. $(F)$ Pattern of immunostaining following induction of LTP using 400-hz stimulation. Note the lack of an increase in immunostaining for $\mathrm{p}$-ERK. The track of the micropipette recording electrode is indicated. (G) Pattern of immunostaining for $p$-ERK on the control (nonstimulated) side of the hippocampus of a mouse that had been anesthetized for $\sim 2.5 \mathrm{~h}$ during a neurophysiological experiment. (H) Lack of induction of ERK1/2 phosphorylation following delivery of $400 \mathrm{~Hz}$ stimulation for $2 \mathrm{~h}$. Note, however, that immunostaining in the mossy fiber (MF) layer is higher on the stimulated side.

except that in mice, the mossy fibers were heavily stained for p-ERK. As in rats, staining for p-ERK was conspicuously different in animals that have been anesthetized for some time (1-2 h), in that there are fewer individual neurons exhibiting high levels of p-ERK staining (Fig. 4D), and the levels of immunostaining of mossy fibers diminished with time in the anesthetized animals (Fig. 4, cf. A and G). These results demonstrate that as in rats, levels of ERK1/2 phosphorylation in mice are regulated by naturally occurring neuronal activity.

Given that induction of perforant-path LTP in rats reliably triggers ERK1/2 phosphorylation, we were surprised to find that there was little, if any, detectable increase in ERK1/2 phosphorylation in mice after inducing LTP. For example, in the mouse whose physiological responses are illustrated in Figure $3 \mathrm{~A}$, in which robust LTP was induced by $400 \mathrm{~Hz}$ stimulation, there was no detectable alteration in immunostaining for p-ERK (Fig. 4F). In this experiment, the animal was killed 30 min after the delivery of the stimulation, when both ERK phosphorylation and IEG induction are evident in rats. Overall, p-ERK immunostaining was assessed in four mice that received $400 \mathrm{~Hz}$ followed by 250 $\mathrm{Hz}$ stimulation and five mice that received only $250 \mathrm{~Hz}$ stimulation; all mice were killed 15-30 min after LTP induction. There was no detectable alteration in immunostaining for p-ERK in six of these mice despite strong induction of LTP. In three other mice, there were slight increases in immunostaining in scattered granule cells in the ventral blade of the dentate gyrus.

Even when high-frequency stimulation was delivered continuously at a rate of one train/10 sec for $1.5 \mathrm{~h}$, there was little alteration in immunostaining for $\mathrm{p}$-ERK in the dentate gyrus except for the presence of a few scattered granule cells exhibiting high p-ERK staining (Fig. 4H). One interesting sidebar, however, was that the mossy fibers on the stimulated side exhibited higher levels of labeling, suggesting that activation of granule cells via the perforant path prevented the decrease in p-ERK staining due to anesthesia.

Similarly, in experiments in which LTP was successfully induced in mice, there was no induction of IEG expression. For example, Figure 5B illustrates the pattern of immunostaining for c-fos 30 min after inducing LTP (from the case illustrated in Fig. 3A). Similar results were seen in six animals killed 20-30 min after delivery of $250 \mathrm{~Hz}(n=2)$ or $400 \mathrm{~Hz}(n=4)$ trains. Even when $400 \mathrm{~Hz}$ trains were delivered every $10 \mathrm{sec}$ for $2 \mathrm{~h}$, there was only a modest increase of IEG expression in mice in a minority of dentate granule cells (Fig. 5D, which illustrates the pattern of immunostaining for Arc). It is important to note that delivering $400 \mathrm{~Hz}$ trains for $2 \mathrm{~h}$ is far more stimulation (720 trains) than is needed to induce persistent LTP (30 trains), and in rats, strongly induces IEG expression in nearly every neuron in the granule cell layer (see Fig. 1).

\section{Mice show strong induction of IEG synthesis following seizures}

One possible explanation for these results is that the signaltransduction pathways that trigger IEG expression are blunted in mice. To test this hypothesis, we assessed IEG expression in mice that had received an electroconvulsive seizure (ECS) prior to being anesthetized, and then received repeated $400 \mathrm{~Hz}$ trains for 2 $\mathrm{h}$ as described above. In rats, this paradigm strongly induces and maintains the expression of a number of IEGs in dentate granule cells, including c-fos and Arc. As illustrated in Figure 5E, IEG expression (in this case c-fos) was strongly induced in dentate granule cells $2 \mathrm{~h}$ after the ECS and continuous high-frequency stimulation. Indeed, the induction seen here is quite comparable to what is seen in rats using the same immunocytochemical techniques (Steward and Worley 2001).

Another possibility is that IEG induction in mice is more sensitive to anesthesia. Strong evidence against this possibility comes from experiments in which seizures were induced during the insertion of the recording electrode, which are easily detected because of the ongoing physiological recordings. This phenomenon occurs occasionally, and in rats, strongly induces IEG expression in dentate granule cells. As illustrated in Figure 5F, IEG 

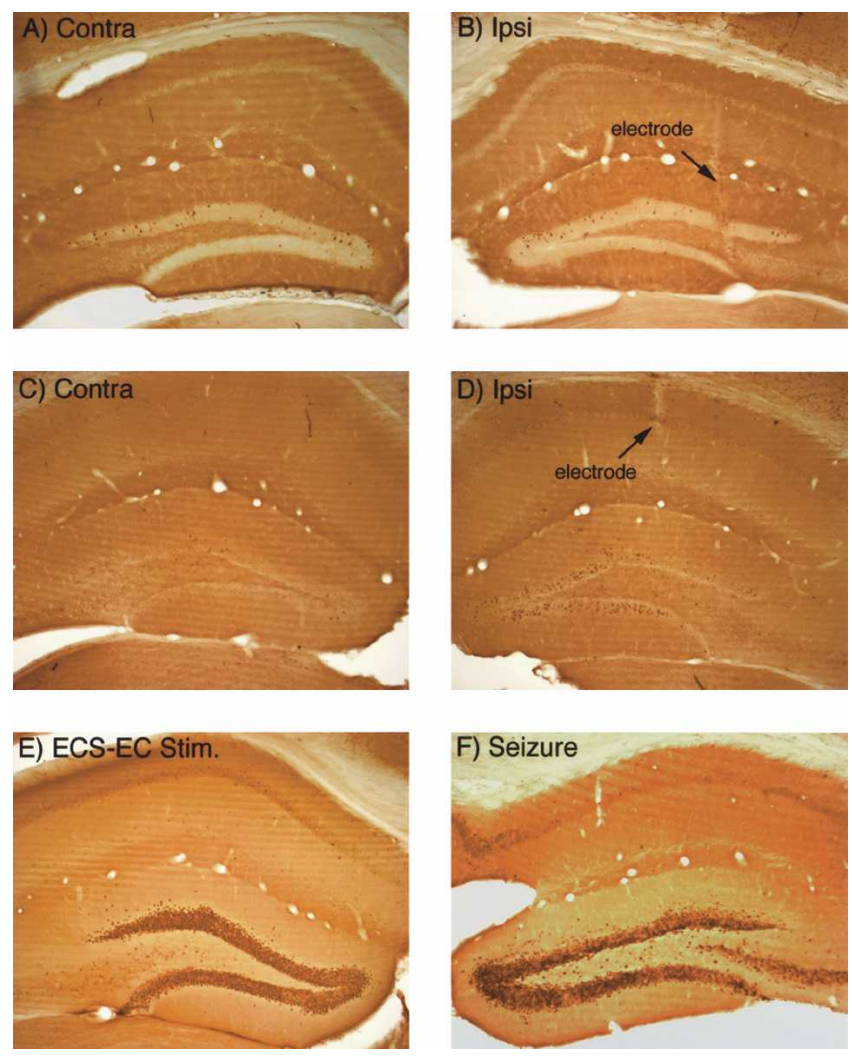

Figure 5. IEG expression is not induced in mice following induction of LTP, but is strongly induced by seizures. $(A, B)$ Pattern of immunostaining for $\mathrm{c}$-fos on the control $(A)$ and stimulated $(B)$ side 30 min after inducing LTP (from the case illustrated in Fig. $3 A$ ). ( $C, D)$ Pattern of immunostaining for Arc on the control $(A)$ and stimulated $(B)$ side after delivery of $400-\mathrm{hz}$ trains every $10 \mathrm{sec}$ for $2 \mathrm{~h}$, which is highly effective in inducing IEG expression in rats. $(E)$ Induction of c-fos expression $2 \mathrm{~h}$ after inducing an electroconvulsive seizure (ECS). ( $F$ Induction of c-fos expression $2 \mathrm{~h}$ after induced during the insertion of the recording electrode.

expression (in this case c-fos) is also strongly induced in mice $2 \mathrm{~h}$ after a seizure triggered by electrode penetration. The induction of IEG expression following seizures demonstrates that signaltransduction pathways that trigger IEG expression are intact in mice and are activated by at least some of the same stimuli that are effective in rats.

\section{In rats, $250 \mathrm{~Hz}$ stimulation induces LTP, but does not reliably trigger ERK1/2 phosphorylation or IEG expression}

Because of the differential effectiveness of the two induction protocols in mice, we were curious as to whether there would be differences in the degree of MAP kinase activation and IEG induction by the two stimulation protocols in rats. Consistent with previous studies, delivery of three to four $250 \mathrm{~Hz}$ trains of 50 pulses each did reliably induce perforant path LTP (Fig. 6). In seven experiments, early LTP was induced in every case (mean increase in EPSP slope-39 $\pm 12 \%$; mean increase in populationspike amplitude $=163 \pm 36 \%$ ). Surprisingly, however, the bouts of $250 \mathrm{~Hz}$ stimulation that were effective in inducing LTP did not induce ERK phosphorylation to the same degree as $400 \mathrm{~Hz}$ stimulation and did not induce IEG expression at all, despite the fact that both stimulation protocols were effective in inducing LTP (Fig. 7). The absence of ERK phosphorylation following the induction of LTP by $250 \mathrm{~Hz}$ trains was initially documented in experiments in which animals were killed 15-20 min post- stimulation (the time at which ERK phosphorylation is strikingly enhanced following $400 \mathrm{~Hz}$ stimulation). In these experiments, there was no detectable change in immunostaining for p-ERK (Fig. 7).

Given that IEG induction is thought to be critical for late phase LTP, the obvious question was whether the form of LTP induced by $250 \mathrm{~Hz}$ stimulation was in fact long lasting. We first addressed this question in a way that also permitted assessment of ERK phosphorylaton and IEG induction in the same animals. LTP was induced by delivering three $250 \mathrm{~Hz}$ trains, and test pulses were then delivered for 60 min to determine the LTP persistence. In three experiments, LTP was maintained over the 1-h

\section{A}
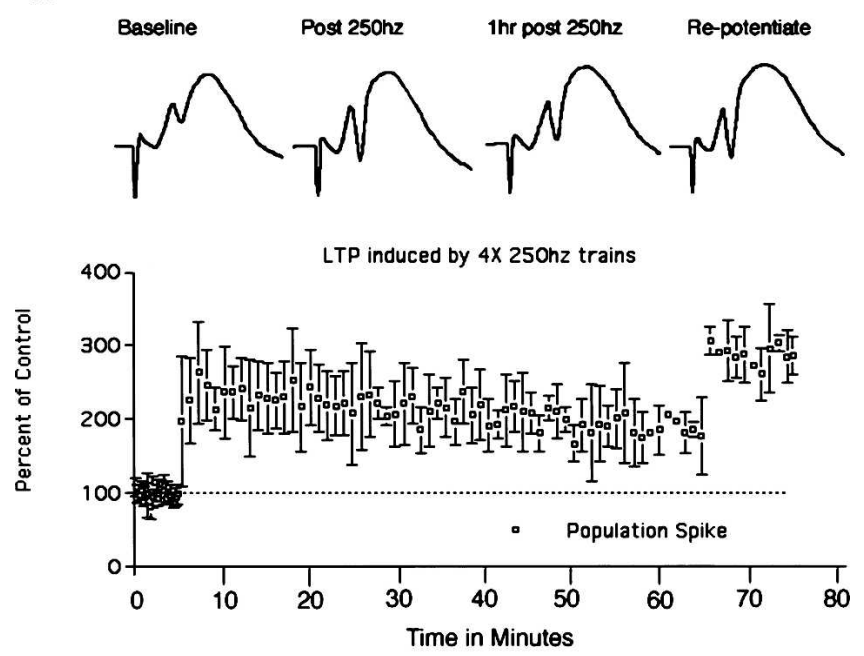

B
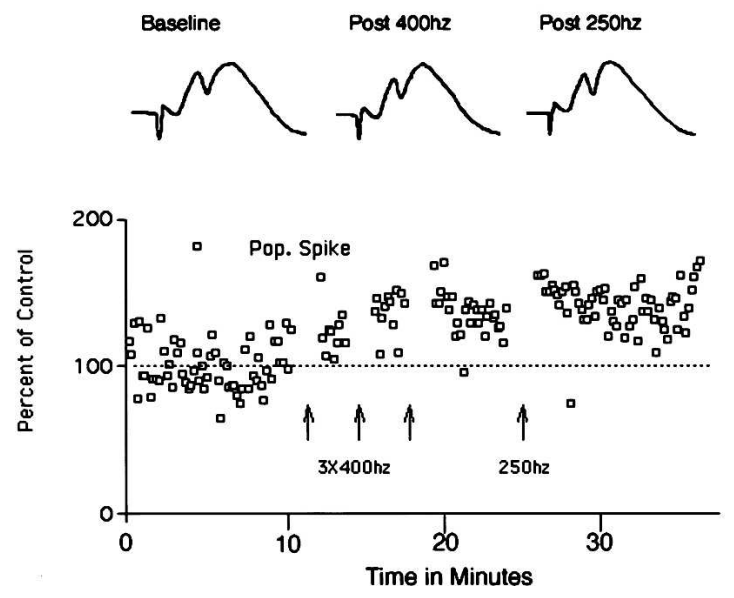

Figure 6. Time course of LTP induced in rats by $250 \mathrm{~Hz}$ stimulation and blockade of induction by NMDA receptor antagonists. (A) Perforant path LTP induced by $250 \mathrm{~Hz}$ stimulation. Traces illustrate positive-going population EPSPS and population spikes recorded by a micropipette positioned in the cell body layer of the dorsal blade of the dentate gyrus. The graph illustrates average population-spike amplitude $( \pm S D)$ as a percent of baseline before and after $250 \mathrm{~Hz}$ stimulation. After testing for $1 \mathrm{~h}$, another set of three $250 \mathrm{~Hz}$ trains was delivered (repotentiate), which produced additional LTP. (B) LTP is blocked when the micropipette recording electrode contains MK801 $(10 \mathrm{mg} / \mathrm{mL})$. Traces illustrate positive-going population EPSPs and population spikes recorded by a micropipette positioned in the cell body layer of the dorsal blade of the dentate gyrus. In this experiment, three bouts of $400 \mathrm{~Hz}$ stimulation were delivered, and then three bouts of $250 \mathrm{~Hz}$ stimulation. Neither produced the LTP that is otherwise seen.

\section{Learning \& Memory}

www.learnmem.org 

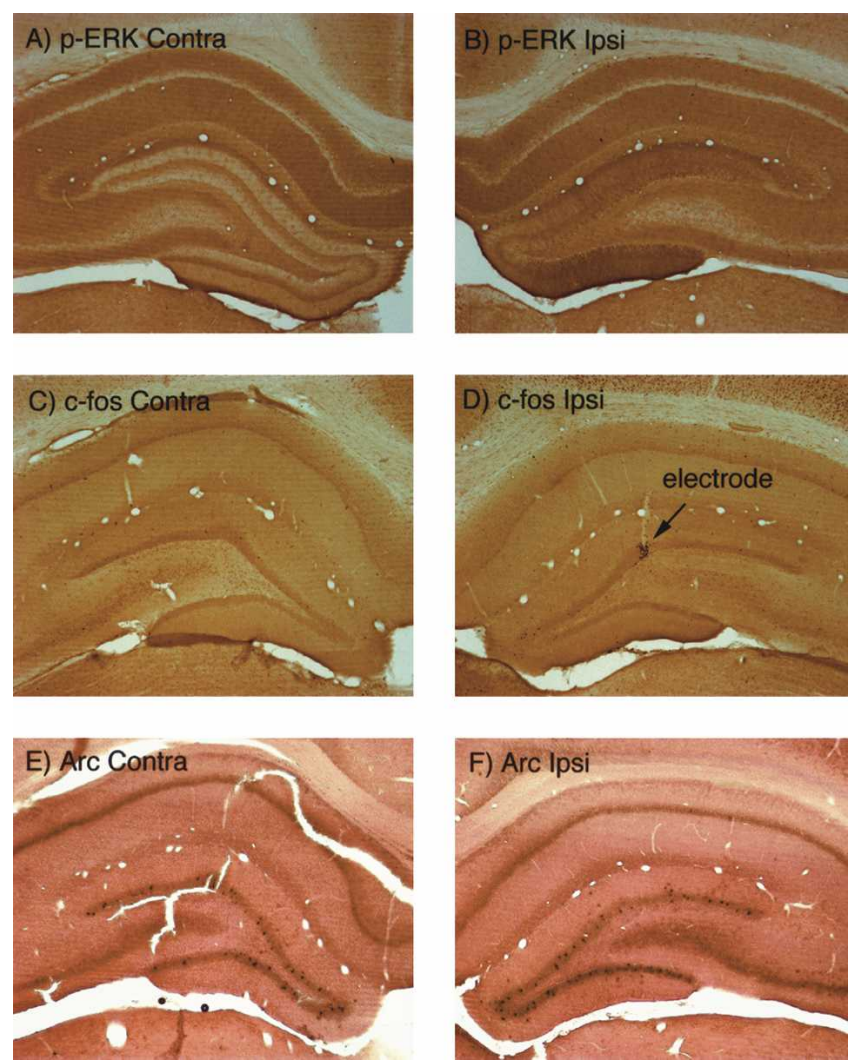

Figure 7. In rats, $250 \mathrm{~Hz}$ stimulation is less effective in inducing ERK $1 / 2$ phosphorylation and IEG expression than $400 \mathrm{~Hz}$ stimulation. $(A, B) \mathrm{Im}$ munostaining for $\mathrm{p}$-ERK on the control $(A)$ and stimulated $(B)$ side $30 \mathrm{~min}$ after inducing LTP by $250-\mathrm{hz}$ stimulation. Note minimal alteration in immunostaining on the stimulated side. $(C, D)$ Immunostaining for c-fos on the control $(C)$ and stimulated $(D)$ side 30 min after inducing LTP by $250 \mathrm{~Hz}$ stimulation. Note the lack of induction of c-fos protein expression on the stimulated side except at the tip of the micropipette recording electrode, where c-fos expression is induced as a result of the local injury. $(E, F)$ In situ hybridization for Arc mRNA on the control $(E)$ and stimulated $(F)$ side $30 \mathrm{~min}$ after inducing LTP by $250 \mathrm{~Hz}$ stimulation. Note the lack of induction of Arc mRNA on the stimulated side.

testing period (Fig. 6A). After completing the 1-h testing, a second bout of $250 \mathrm{~Hz}$ stimulation was delivered to determine whether the potentiation induced in the first bout was saturating. As illustrated in Figure 6A, the second bout of stimulation did induce additional potentiation. Animals were then allowed to survive for 10-15 min after the second round of $250 \mathrm{~Hz}$ stimulation, and were then perfused. In this paradigm, any IEG induction induced by the first round of stimulation would be evident by increases in IEG protein levels $1 \mathrm{~h}$ and 15 min later. In addition, ERK phosphorylation induced by the second round of stimulation would be evident by increases in p-ERK staining. Nevertheless, although the survival times would have been optimal for detecting both ERK phosphorylation and IEG induction, there was only a modest change in immunostaining for p-ERK (Fig. 7A,B) and there was no detectable increase in IEG protein expression as assessed by immunostaining for c-fos (Fig. 7C,D). Tissue from these cases was also prepared for in situ hybridization for Arc mRNA to detect IEG mRNA transcription in response to the second bout of stimulation, and again, there was no detectable induction of Arc transcription (Fig. 7E,F).

Although the experiment above demonstrates that LTP was maintained for $1 \mathrm{~h}$ in the absence of ERK phosphorylation or IEG induction, it still remains possible that the LTP induced by 250
$\mathrm{Hz}$ stimulation is not as enduring as the LTP produced by $400 \mathrm{~Hz}$ stimulation. Accordingly, we undertook experiments to directly compare the persistence of LTP induced by the two paradigms. For these experiments, recording electrodes were positioned in the hilus to allow simultaneous recordings of the positive-going field EPSP and population spike. LTP was induced by delivering $3 \times 10400 \mathrm{~Hz}$ trains $(n=4)$ or six $250 \mathrm{~Hz}$ trains $(n=6)$, and test responses were collected for a minimum of $3 \mathrm{~h}$, and for up to $6 \mathrm{~h}$ in some cases. The graphs of Figure 8, which plot the average EPSP slope and population-spike amplitudes for the two groups, document that LTP produced by $250 \mathrm{~Hz}$ stimulation persisted with minimal decrement for at $3 \mathrm{~h}$ in all $(n=6)$ animals. In addition, in two animals that were tested for $6 \mathrm{~h}$, LTP of both the population spike and the field EPSP was still evident (data not shown).

\section{Does $250 \mathrm{~Hz}$ stimulation induce transient transcriptional activation?}

There is evidence that the induction of LTP in the CA1 region induces only a brief burst in IEG transcription lasting only a few minutes (as measured by transcriptional activation of Arc; $\mathrm{O}$. Steward and J.F. Guzowski, unpubl.), as is also true for behavioral activation of transcription in CA1 (Vazdarjanova et al. 2002). This is in contrast to the transcriptional induction seen after inducing LTP in the dentate gyrus using $400 \mathrm{~Hz}$ stimulation that persists for at least $1-2 \mathrm{~h}$. Thus, it was of interest to determine whether $250 \mathrm{~Hz}$ stimulation was completely ineffective in inducing IEG transcription (as would be predicted by the lack of activation of MAP kinase) or, instead, induced a brief transient transcriptional activation. To address this question, perforant path LTP was induced by $250 \mathrm{~Hz}$ stimulation, and animals were killed 5 min later. Transcriptional activation was assessed using catFISH, which reveals transcriptional foci for Arc mRNA in the nucleus within minutes after activation (Guzowski et al. 1999). Transcriptional foci were evident in dentate granule cells $\sim 5 \mathrm{~min}$ after stimulation at $400 \mathrm{~Hz}$ (Fig. 9, cf. A and B), but not after stimulation at $250 \mathrm{~Hz}$ (Fig. 9C,D).

\section{Is stimulus number critical?}

The $400 \mathrm{~Hz}$ stimulation paradigm involves the delivery of 30 eight-pulse trains for a total of 240 pulses. In contrast, the $250 \mathrm{~Hz}$ paradigm involves the delivery of 150 pulses. It is conceivable that the difference in the total number of pulses accounts for the differential effectiveness in activating MAP kinase and inducing IEG expression. To address this question, we carried out experiments in four additional animals in which six $250 \mathrm{~Hz}$ trains were delivered, animals were killed $30 \mathrm{~min}$ later, and sections were stained for p-ERK and Arc protein. In three cases, there was no hint of any activation of ERK phosphorylation or IEG induction, and in the fourth case, there was only a slight alteration in p-ERK immunostaining in the area surrounding the recording electrode, which is probably due to the slight damage produced by the electrode (data not shown).

Although ERK phosphorylation and IEG expression are not induced by three to six rounds of $250 \mathrm{~Hz}$ stimulation, both are induced when stimulation at $250 \mathrm{~Hz}$ is delivered continuously for 1-2 h (Fig. 9I,J). Thus, prolonged stimulation apparently exceeds a threshold for inducing ERK phosphorylation and IEG expression that is not achieved by more limited bouts of stimulation that are nevertheless effective in inducing LTP.

\section{LTP induced by both $400 \mathrm{~Hz}$ and $250 \mathrm{~Hz}$ trains requires NMDA receptor activation}

IEG induction following $400 \mathrm{~Hz}$ stimulation is blocked by the NMDA receptor antagonists MK801 and APV (Steward and Wor- 

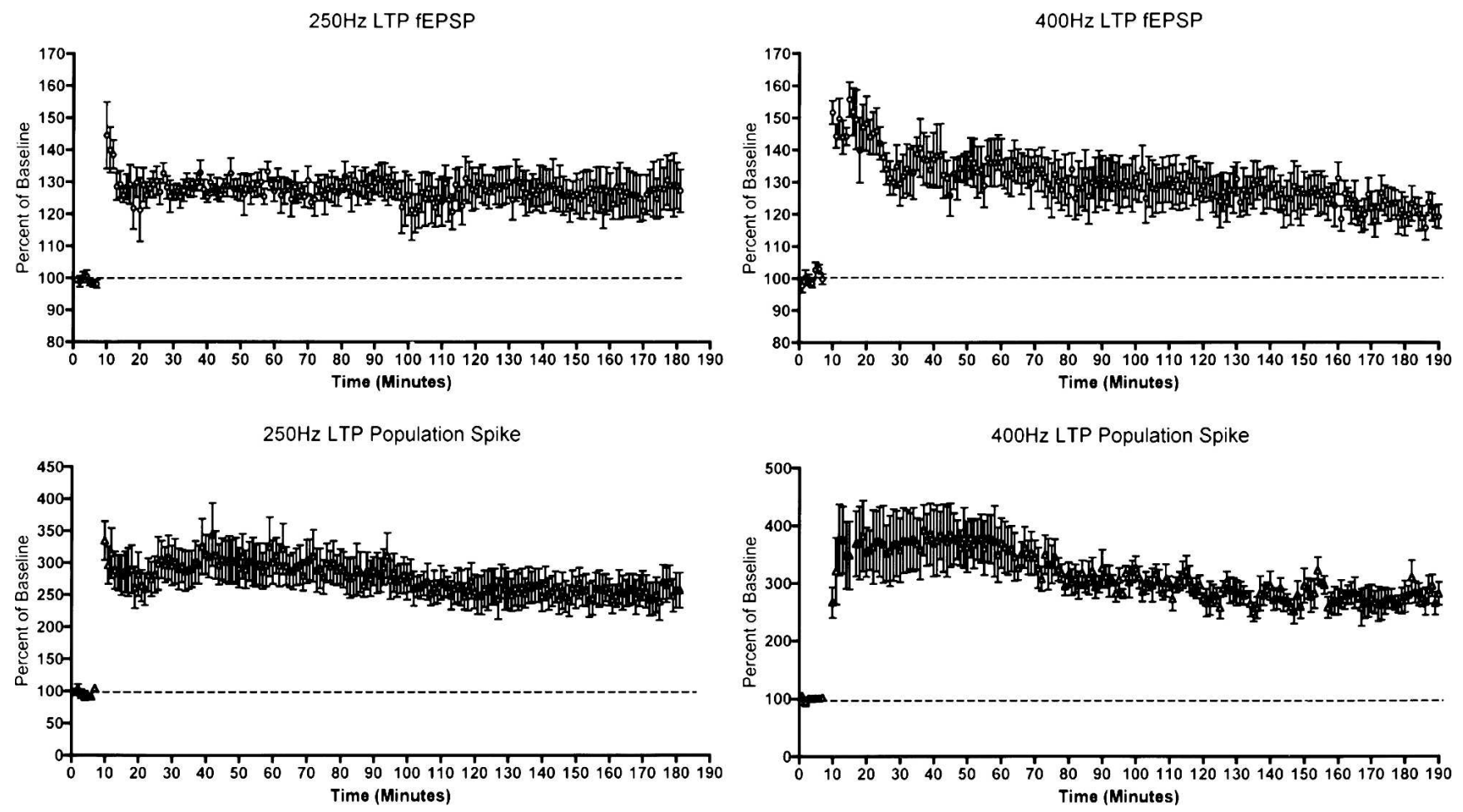

Figure 8. Comparison of the longevity of LTP induced by 400 versus $250 \mathrm{~Hz}$ stimulation in rats. The graphs illustrate average amplitude of the field EPSP and population spike before and after delivery of $3 \times 10$ trains at $400 \mathrm{hz}$ ( $n=4$ rats) and six 250-hz trains ( $n=6$ rats). Both stimulation paradigms produce stable LTP that persists for the duration of the experiment (over $3 \mathrm{~h}$ ).

ley 2001). NMDA receptor antagonists also block ERK phosphorylation (J. Chotiner, F. Huang, and O. Steward, unpubl.), indicating that both MAP kinase activation and IEG induction are mediated by NMDA receptor activation. Because $250 \mathrm{~Hz}$ stimulation can induce LTP without activating MAP kinase or inducing IEGs, it was of interest to determine whether the LTP induced by $250 \mathrm{~Hz}$ stimulation depended on NMDA receptor activation. To address this question, we used the technique in which the recording micropipette contains the NMDA receptor antagonist (in this case, MK801), which blocks NMDA receptors in a local region around the micropipette tip (Steward and Worley 2001). As in previous studies, local delivery of MK801 blocked LTP following $400 \mathrm{~Hz}$ stimulation (Fig. 6B) and also blocked LTP that would otherwise occur with $250 \mathrm{~Hz}$ stimulation. The slight potentiation that is seen (note difference in $\mathrm{Y}$ axis scale between Fig. 6A and Fig. 6B) reflects the fact that NMDA receptor blockade occurs in a local area surrounding the micropipette tip, and there is some volume conduction of the evoked potentials from distant sites when recording at the layer of the granule cell bodies (Steward and Worley 2001).

\section{Pharmacological blockade of ERK phosphorylation} in rats does not block the induction of LTP

If perforant path LTP can occur in mice in the absence of ERK phosphorylation, the obvious prediction is that LTP could occur in rats if ERK phosphorylation was blocked pharmacologically. We tested this hypothesis by injecting the MEK inhibitor UO126 into the dentate gyrus before inducing LTP with $3 \times 10$ trains at $400 \mathrm{~Hz}$. As illustrated in Figure 10, UO126 blocked the ERK phosphorylation that was otherwise seen 15 min after delivering HFS. Nevertheless, perforant-path LTP was comparable to what is seen in control rats. In five experiments with verified blockade of ERK phosphorylation by UO126, the average increase in EPSP slope and population-spike amplitude immediately after high-frequency stimulation at $400 \mathrm{~Hz}$ was $47 \pm 25$ and $144 \pm 94$, respectively (mean $\pm \mathrm{SD}$ ). In five control experiments carried out during the same time period, the average increase in EPSP slope and population-spike amplitude immediately after high-frequency stimulation at $400 \mathrm{~Hz}$ was $43 \pm 24$ and $304 \pm 209$, respectively. In these experiments, we tested responses for only 15-30 min after inducing LTP because ERK phosphorylation is transient, and returns to near control levels by $1 \mathrm{~h}$ after stimulation (J. Chotiner, F. Huang, and O. Steward, in prep.). Thus, it is possible that the late phase of LTP would have been attenuated in UO126-treated rats. Nevertheless, these results indicate that LTP induction is comparable in the absence of ERK phosphorylation.

In rats, induction of LTP with either $400 \mathrm{~Hz}$ or $250 \mathrm{~Hz}$ stimulation triggers polymerization of actin in the activated dendritic lamina

We were curious as to whether other molecular correlates of perforant path LTP were seen in the form of LTP in rats that is induced by $250 \mathrm{~Hz}$ stimulation. For example, one molecular/ structural correlate of inducing perforant path LTP with $400 \mathrm{~Hz}$ stimulation is a striking reorganization of the actin cytoskeleton involving increases in actin polymerization, which can be revealed by staining for phalloidin (Fukazawa et al. 2003). This phenomenon is of interest because it could represent part of the structural alteration in spines that accompanies LTP. As illustrated in Figure 11B, a striking band of increased phalloidin staining was evident in rats that were perfused after inducing LTP with $400 \mathrm{~Hz}$ stimulation and then continuing HFS stimulation for an additional $15 \mathrm{~min}$. The control pattern of staining is illustrated in Figure 11A. The striking band of increased staining is fully developed immediately after the delivery of 30 trains to induce LTP (F. Huang, J. Chotiner, and O. Steward, in prep.). A similar band of 

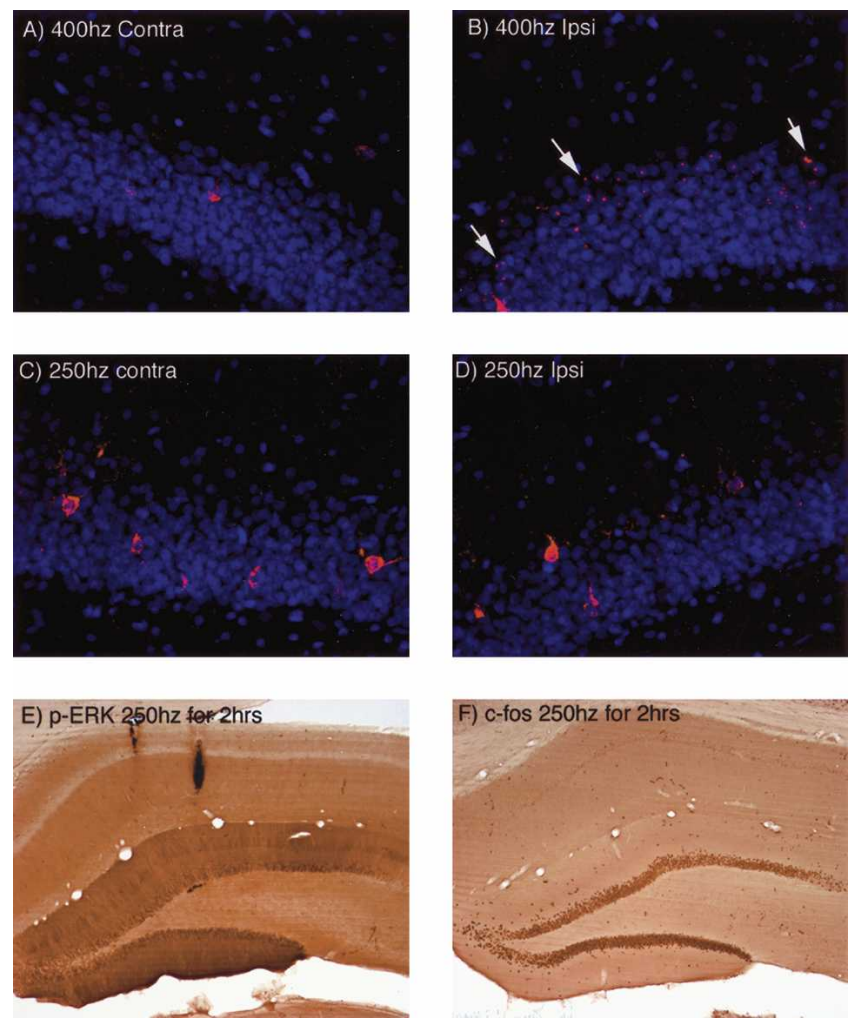

Figure 9. CatFISH reveals that Arc transcription is induced by $400 \mathrm{~Hz}$ stimulation, but not by $250 \mathrm{~Hz}$ stimulation. $(A, B)$ ARC mRNA expression as revealed by catFISH 5 min after inducing LTP with $400 \mathrm{~Hz}$ stimulation. Note transcriptional foci in the nucleus of the granule cells on the side of the stimulation. $(B, C)$ The lack of induction of ARC transcription as revealed by catFISH 5 min after inducing LTP with $250 \mathrm{~Hz}$ stimulation. $(E, F)$ Pattern of immunostaining for p-ERK and c-fos after delivery of $250 \mathrm{~Hz}$ stimulation at a rate of one train per minute for $2 \mathrm{~h}$.

increased phalloidin staining was seen after induction of LTP in rats by $250 \mathrm{~Hz}$ stimulation (Fig. 11D). As previously shown for LTP induced by $400 \mathrm{~Hz}$ stimulation (Fukazawa et al. 2003), the prominent band of enhanced phalloidin staining was still evident in all of the cases that were killed 3-6 h after inducing LTP with $250 \mathrm{~Hz}$ stimulation from the experiment illustrated in Figure 8 (data not shown). In contrast, phalloidin staining of sections from mice in which LTP had been induced by $250 \mathrm{~Hz}$ stimulation revealed only a hint of a band of polymerized actin. Figure $11 \mathrm{~F}$ illustrates the case (of four tested) with the most prominent alteration in phalloidin staining, and even here the band of staining is barely detectable. Thus, actin polymerization is reliably seen after induction of LTP in rats regardless of the stimulation paradigm used, but is not reliably seen in mice.

It is noteworthy that there was also a slight band of increased phalloidin staining on the side contralateral to the stimulation in rats (Fig. 11A,C). This is not seen in unstimulated animals (data not shown), and probably represents the activation of the sparse crossed pathway from the entorhinal cortex to the contralateral dentate gyrus (the crossed temporo-dentate pathway) (see Steward 1976).

\section{Discussion}

Our findings reveal that the association between the induction of perforant path LTP and its purported molecular correlates depends on the stimulation paradigm used $(400 \mathrm{~Hz}$ versus $250 \mathrm{~Hz}$ stimulation) and on the species (rat versus mice). The fact that
LTP can be induced in the absence of MAP kinase activation and induction of gene expression raises questions about what has previously seemed to be a compelling mechanistic hypothesis regarding protein synthesis-dependent synaptic modifications of perforant path synapses. Our results indicate that there are different forms of perforant path LTP that are activated by different stimulation paradigms, and that one form of perforant path LTP can occur without triggering ERK1/2 phosphorylation or IEG induction. Thus, caution is required in generalizing across species, stimulation paradigms, or brain regions with regard to molecular processes that occur following the induction of LTP. In what follows, we consider some of the technical issues raised by our findings, and the implications for our understanding of molecular mechanisms of synaptic plasticity.

\section{Technical considerations}

Different groups have used $400 \mathrm{~Hz}$ versus $250 \mathrm{~Hz}$ stimulation paradigms to induce perforant path LTP, and the tacit assumption has been that the two forms of stimulation trigger the same signal-transduction events and ultimate synaptic modifications (or at least there has been no report to the contrary). In the present experiments, $400 \mathrm{~Hz}$ stimulation in rats induced perforant path LTP that was associated with ERK phosphorylation and IEG induction; $250 \mathrm{~Hz}$ stimulation induced LTP with no ERK
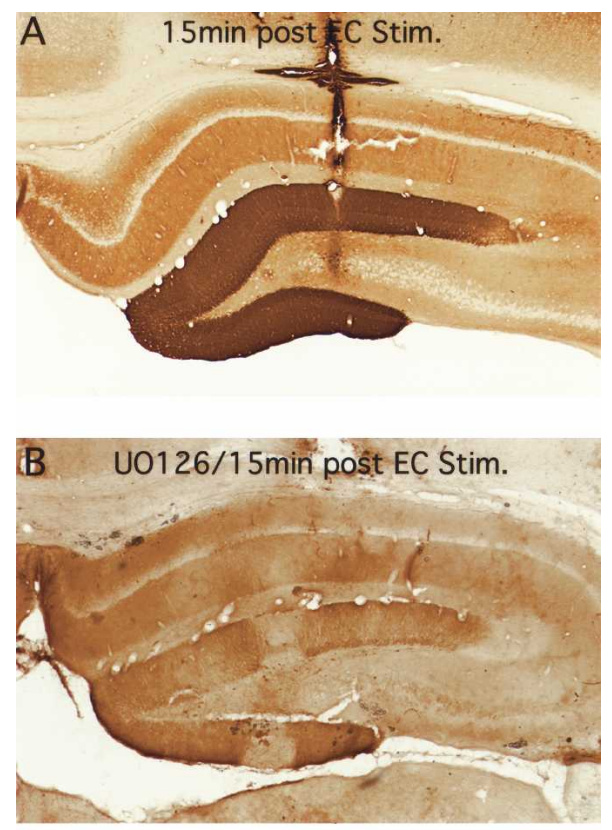

C

$$
\text { Post-U0126 15min. post EC Stim. }
$$
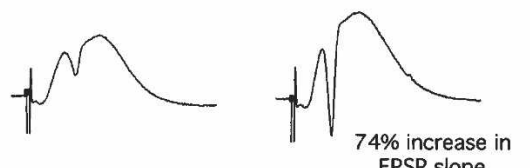

EPSP slope

Figure 10. UO126 blocks ERK phosphorylation induced by $400 \mathrm{~Hz}$ stimulation, but does not block early LTP. (A) Pattern of immunostaining in control animals $15 \mathrm{~min}$ after inducing LTP. (B) Pattern of immunostaining for $\mathrm{p}$-ERK in animals that received injections of UO126 via a Hamilton microsyringe $15 \mathrm{~min}$ prior to delivering $400 \mathrm{~Hz}$ stimulation. Note complete blockade of ERK phosphorylation. (C) Responses evoked by perforant-path stimulation in the same animal illustrated in $B$ after UO126 but before $400 \mathrm{~Hz}$ stimulation and $15 \mathrm{~min}$ after stimulation. 

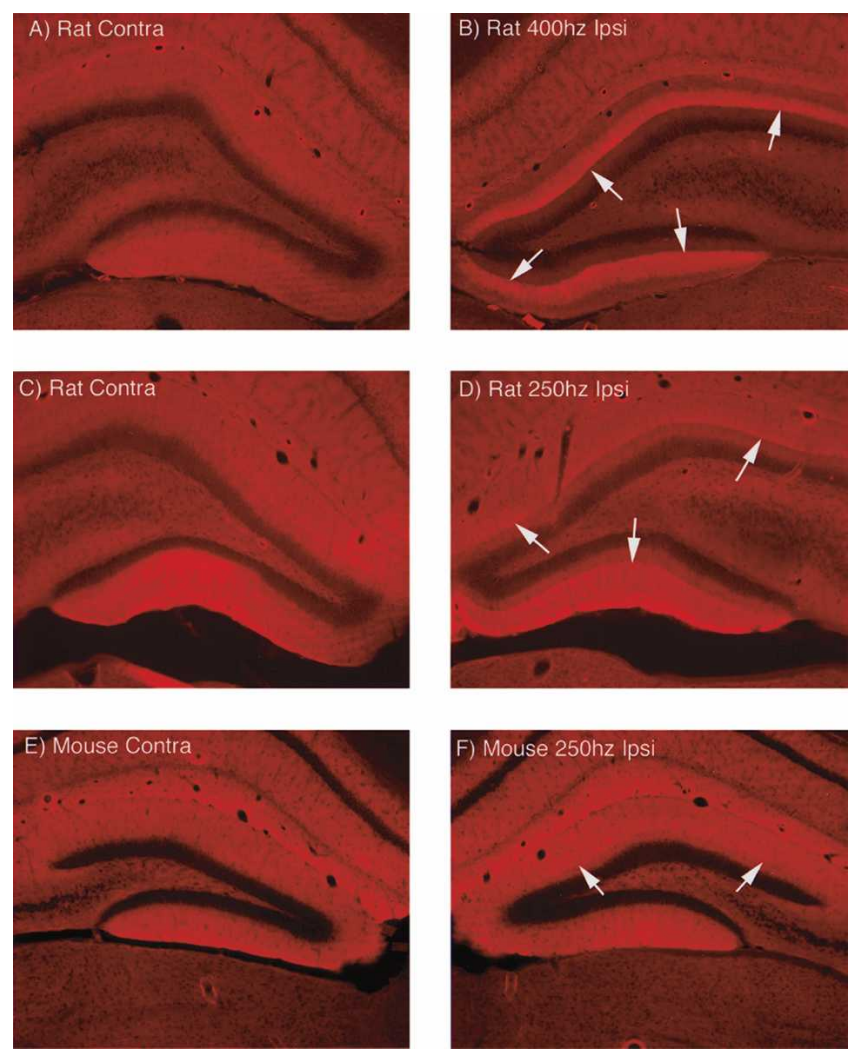

Figure 11. In rats, induction of LTP with either 400 or $250 \mathrm{~Hz}$ stimulation triggers polymerization of actin in the activated dendritic lamina, but this is not seen in mice. $(A, B)$ Pattern of staining for phalloidin on the control $(A)$ and stimulated $(B)$ side 30 min after inducing LTP in rats by $400 \mathrm{~Hz}$ stimulation. Note the striking band of staining in the middle molecular layer on the side of the stimulation. $(C, D)$ Pattern of staining for phalloidin on the control $(A)$ and stimulated $(B)$ side 30 min after inducing LTP in rats by $250 \mathrm{~Hz}$ stimulation. (E, $P$ ) Pattern of staining for phalloidin on the control $(A)$ and stimulated $(B)$ side 30 min after inducing LTP in mice by $250 \mathrm{~Hz}$ stimulation. Note minimal alteration in staining on the stimulated side.

phosphorylation or IEG induction, and neither form of stimulation reliably triggered ERK phosphorylation or IEG induction in mice, even though LTP was induced. Nevertheless, the two induction paradigms triggered synaptic modifications that were dependent on NMDA receptor activation, suggesting common induction mechanisms. Also, in mice, $250 \mathrm{~Hz}$ stimulation was more reliable in inducing LTP, although LTP was seen in mice in experiments involving higher intensity stimulation at $400 \mathrm{~Hz}$.

It should be noted that previous studies have reported that $400 \mathrm{~Hz}$ stimulation is effective in inducing LTP in urethaneanesthetized mice (Jones et al. 2001b). One possible explanation is a procedural difference. In our experiments, the intensity of the individual pulses during the train was the same as during the test period. In contrast, in the study by Jones et al. (2001b), pulse width was doubled during the train, which would increase the current and the effective stimulus intensity. Thus, higher intensity stimulation at $400 \mathrm{~Hz}$ may be more reliable in inducing LTP in mice. This does not, however, compromise the conclusion that $250 \mathrm{~Hz}$ stimulation is effective at a lower intensity in mice, and can induce LTP with minimal activation of ERK phosphorylation or IEG induction.

It is important to note that we assessed LTP occurrence in mice primarily based on measures of the population spike because of technical difficulties in carrying out reliable long-term recordings of the population EPSP. Accordingly, we cannot ex- clude the possibility that the stimulation paradigms used here induce population-spike LTP in mice, but not long-term increases in population EPSP slope. This would, however, mean that mice exhibit a different form of perforant path LTP than is seen in rats, in which there is stable LTP of both population spike and EPSP. Although this possibility cannot be excluded, we favor the more parsimonious explanation that stable LTP of the population spike indicates stable LTP of the population EPSP.

\section{Do perforant path synapses have the capacity} for several different LTP-like phenomena?

Regarding the two stimulation paradigms, there are several possible interpretations of our findings. For example, it is possible that the two stimulation paradigms induce completely different synaptic modifications, and only the form induced by $400-\mathrm{hz}$ stimulation involves ERK phosphorylation and IEG induction. Another possibility is that 400-hz stimulation actually induces two forms of LTP, only one of which involves ERK phosphorylation and IEG induction, whereas $250 \mathrm{~Hz}$ stimulation induces only the form of LTP that is NOT associated with ERK phosphorylation and IEG induction. In either of these scenarios, our data indicate that the form of LTP that requires ERK phosphorylation and IEG induction is not reliably induced in mice by the stimulation paradigms we have used. Other enigmatic features of perforant path LTP in mice have also been noted (Jones et al. 2001a).

Considering these conclusions within the context of the hypothesis that L-LTP requires MAP kinase activation and IEG expression, the implication would be that $400 \mathrm{~Hz}$ stimulation would induce L-LTP in rats but not mice, and $250 \mathrm{~Hz}$ stimulation would trigger only the form of LTP that does not require IEG induction.

\section{When does perforant path LTP decay in the absence of IEG induction?}

Our results demonstrate that $250 \mathrm{~Hz}$ stimulation can induce LTP that persists for at least $6 \mathrm{~h}$, despite the absence of IEG induction. If IEG induction is required for late-phase perforant path LTP, it is not clear when synaptic modifications deteriorate in the absence of IEG induction. A critical role for one IEG has been demonstrated in studies that used antisense oligonucleotides to disrupt expression of Arc following induction of LTP; here, antisense oligonucleotides impaired maintenance of perforant path LTP over days, as measured using chronic stimulation and recording techniques (Guzowski et al. 2000). Here, however, we demonstrate an absence of induction of both Arc and c-fos, suggesting a general impairment of IEG induction, which could have more severe consequences than disrupting expression of only one IEG. In studies of perforant path LTP in awake rats, treatment with the protein synthesis inhibitor anisomycin, which would block expression of all IEGs as well as other proteins, caused LTP that had been induced by brief 400 -hz trains to decay to baseline levels within about 3-4 h (Otani et al. 1989). In more recent studies in urethane-anesthetized animals, however, LTP induced by 1-sec-long $400 \mathrm{~Hz}$ trains was maintained in the presence of the protein synthesis inhibitor cycloheximide for $5 \mathrm{~h}$, and only then began to decay in comparison with the LTP in untreated control animals (Fukazawa et al. 2003). The fact that LTP decayed more slowly in anesthetized animals treated with cycloheximide could reflect an effect of the anesthetic, an induction of competing synaptic modifications in awake behaving animals, differences in the protein synthesis inhibitor (anisomycin versus cycloheximide), or could reflect the fact that longer $400 \mathrm{~Hz}$ trains were in the experiments by Fukazawa et al (2003). It should also be noted that Otani et al. (1989) reported that local injections of inhibitors of transcription (actinomycin-D) did not block the late phase of

\section{Learning \& Memory}


perforant path LTP. There are technical issues that could explain the lack of inhibition following local injections of actinomycin$\mathrm{D}$, but this again raises the possibility that perforant path LTP can persist for long periods of time in the absence of full-scale IEG induction.

We did not follow LTP for more than $6 \mathrm{~h}$ to determine when (and if) the response returns to baseline levels. Indeed, the technical complication is that the molecular events that we are studying (especially ERK phosphorylation) occur during the early postinduction period, and do not persist long enough to be detected in experiments in which synaptic potentiation is followed for hours. Studies using chronic stimulation and recording techniques document that perforant path LTP persists for up to $1 \mathrm{yr}$ (Abraham et al. 2002). The LTP that is seen in the absence of ERK phosphorylation and IEG induction might be stable for days or months, or might be a more transient form of plasticity. The readout under acute conditions (that is, for several hours) looks equivalent at the electrophysiological level to perforant path LTP measured in chronically implanted animals at the same time points. In any case, our experiments do confirm that the LTP induced in our experiments by $250 \mathrm{~Hz}$ stimulation persists without decrement for at least 3-6 h, and is indistinguishable from L-LTP described in other studies at this time point.

\section{Induction of LTP in rats triggers polymerization of actin in the activated dendritic lamina}

It is noteworthy that one molecular/structural alteration occurs across stimulation paradigms - the dramatic polymerization of actin in the activated dendritic lamina. Other studies have shown that a similar phenomenon occurs in the induction of LTP in the Schaffer collateral system by $\theta$-burst stimulation, and that the polymerization of actin occurs in spines (Lin et al. 2005; Kramar et al. 2006). The induction of actin polymerization is of considerable interest because it persists for days (Fukazawa et al. 2003), making it the longest lasting of the known molecular correlates of LTP. The fact that this alteration in the actin network is not reliably seen in mice is another indication of a species difference in molecular correlates of LTP.

\section{Conclusion}

The present findings further expand our understanding that there are a number of different LTP-like phenomena. All forms of LTP have a similar readout (long-lasting increases in synaptic efficacy), and it has only been through the study of mechanisms that different types of LTP have been revealed. Previous studies have revealed a number of different forms of hippocampal LTP, some of which are sensitive to protein and RNA synthesis inhibitors (Nguyen et al. 1994), some of which are sensitive only to protein synthesis inhibitors, some of which involve local protein synthesis in dendrites (for review, see Steward and Schuman 2001), and some of which are mediated by presynaptic changes (mossy fiber LTP for example). Until now, it has been reasonable to assume that different patterns of high-frequency stimulation of the medial perforant path trigger a single form of LTP. Our findings, however, reveal that there are different forms of perforant-path LTP that can be induced in rats with different stimulation protocols, and that occur differentially in rats vs. mice. Accordingly, it is important not to generalize too much in drawing conclusions about cellular and molecular correlates. In particular, it will be important to qualify conclusions about the necessity and sufficiency of molecular processes in terms of the exact induction paradigms, species, and pathways involved. Defining the distinct forms of LTP and their specific molecular correlates, as we have begun to do here, will allow us to gain a deeper understanding of the varied ways neurons can implement lasting changes in synaptic efficacy.

\section{Materials and Methods}

\section{Neurophysiological techniques}

Experimental animals were adult male $\mathrm{C} 57 \mathrm{Bl} / 6$ mice and adult male (300-450 g) Sprague-Dawley rats. Animals were anesthetized with urethane and positioned in a stereotaxic apparatus as described previously (Steward et al. 1998). Stimulating and recording electrodes were positioned stereotaxically, so as to activate the pathway from the medial entorhinal cortex (EC) while recording in the dentate gyrus.

For experiments in rats, a monopolar stimulating electrode (an insulated tungsten microelectrode) was positioned at 4.0 lateral to the midline and $1.0 \mathrm{~mm}$ anterior to the transverse sinus. The depth of the stimulating electrode was adjusted so as to obtain a maximal evoked response in the dentate gyrus at minimal stimulus intensity. Recording electrodes were glass micropipettes filled with $0.9 \%$ saline that were positioned at 3.5 posterior to bregma and 1.5-2.0 $\mathrm{mm}$ lateral to the midline. The recording electrodes were positioned in the dorsal blade dentate gyrus based on the evoked responses generated by EC stimulation.

For experiments in mice, the stimulating electrode was positioned $3 \mathrm{~mm}$ lateral to the midline at the transverse sinus. The recording electrode was positioned at 2.5 posterior to bregma and 1.5-1.8 lateral to the midline. Depths of stimulating and recording electrodes were adjusted based on the evoked responses generated by EC stimulation.

After positioning the stimulating and recording electrodes, stimulus intensity was set so as to evoke an $\sim 3-8 \mathrm{mV}$ population spike (measured from the baseline of the positive-going population EPSP). Other intensities of stimulation were used in some experiments, as detailed in the Results. Single test pulses were then delivered at a rate of $1 / 10 \mathrm{sec}$ for $5-20 \mathrm{~min}$ so as to determine baseline response amplitude. Measures included the slope $(\mathrm{mV} / \mathrm{msec})$ of the population EPSP and the amplitude of the population spike as defined above. Values in graphs are expressed as a percentage of the baseline slope or amplitude.

LTP was induced using one of two paradigms: (1) $10400 \mathrm{~Hz}$ trains (20 msec in duration for a total of eight pulses per train) were delivered at a rate of one train/10 sec. This was repeated three times, collecting 10 test responses between each bout of stimulation, so that the three sets of trains occurred $1 \mathrm{~min}, 40 \mathrm{sec}$ apart; (2) either three or six $250 \mathrm{~Hz}$ trains $(200 \mathrm{msec}$ in duration, for a total of 50 pulses) were delivered at 30-sec intervals. In each case, the high-frequency trains were delivered at the same intensity as the test stimulus. In some experiments involving mice, higher intensities were tested, ranging up to intensities that evoked $10 \mathrm{mV}$ population spikes. After the bout of highfrequency stimulation, test responses were delivered in order to determine the extent of the synaptic potentiation that had been induced. In some experiments, high-frequency stimulation (trains at 400 or $250 \mathrm{~Hz}$ ) were delivered continuously at a rate of $1 / 10 \mathrm{sec}$ for various periods of time, as detailed in the results.

To assess the duration of LTP induced by the two stimulation paradigms, a separate set of animals was prepared $(n=4$ for studies of LTP following 400-hz stimulation and $n=5$ for studies of LTP following $250 \mathrm{~Hz}$ stimulation). LTP was induced as described above delivering $3 \times 10400 \mathrm{~Hz}$ trains or six $250 \mathrm{~Hz}$ trains. The first 20 test responses after the high-frequency stimulation were taken at a rate of $1 / 10 \mathrm{sec}$, and then test responses were collected at $1 / 60 \mathrm{sec}$ for at least $3 \mathrm{~h}$ and up to $6 \mathrm{~h}$ as described further in the results.

\section{Local delivery of pharmacological agents}

To deliver pharmacological agents, recording micropipette electrodes were prepared by breaking back the tips of the electrodes so that the internal diameter of the tip was 30-50 $\mu \mathrm{m}$. To block NMDA receptors, micropipettes were filled with a $0.9 \%$ saline solution containing either MK801 at a concentration of $10 \mathrm{mg} /$ $\mathrm{mL}$ or APV at a concentration of $5 \mathrm{mg} / \mathrm{mL}$. MK801 was obtained 
from Tocris Cookson, Inc. APV was obtained from Research Biochemicals International. To block ERK phosphorylation, the MAP kinase-kinase (MEK) inhibitor UO126 was dissolved in DMSO, and then $0.9 \%$ saline was added to make a $20 \%$ DMSO solution with $200 \mu \mathrm{M}$ UO126. UO126 was delivered into the dentate gyrus either by making direct injections of $0.1-0.2 \mu \mathrm{L}$ via a Hamilton microsyringe fitted with a pulled glass micropipette or by filling a micropipette as above and allowing diffusion from the tip.

\section{Immunocytochemistry}

At the termination of the neurophysiological experiment, animals received an overdose of anesthetic (Nembutal or Euthasol) and were perfused within 2-4 min after being removed from the stereotaxic with $4 \%$ paraformaldehyde. The brains were removed and stored in fixative at least overnight, and often for many days (storage in fixative did not interfere with immunostaining). Brains were sectioned in the coronal plane on a Vibratome, and sections were collected and stored in phosphate buffer ( $\mathrm{pH} 7.4)$.

For immunocytochemistry, free-floating vibratome sections were treated with $\mathrm{H}_{2} \mathrm{O}_{2}$ to block endogenous peroxidase. For all of the antibodies used here, sections were heated to $95^{\circ} \mathrm{C}$ for 5 min for antigen retrieval. After antigen retrieval, sections were blocked for $2 \mathrm{~h}$ at RT in 10\% normal goat serum, then incubated in the following primary antibodies: (1) rabbit polyclonal antibody for the phosphorylated form of ERK1/2 (Cell Signaling, Catalog \#9101S, lot \#19, 1:100 dilution); (2) Rabbit polyclonal antibody to c-fos (Santa Cruz Biotechnology, Catalog\# sc-52, lot L1404); Rabbit polyclonal antibody to Arc (generously provided by Paul Worley, Johns Hopkins University, 1:200 dilution). Sections were incubated for $24 \mathrm{~h}$ in the primary antibody, and were then washed and incubated in the secondary antibody (goat antirabbit IgG that was used at a dilution of 1:100 in normal goat serum). Subsequent immunocytochemical procedures were as described in Wallace et al. (1998).

The specificity of the primary antibodies used here has been extensively documented. The polyclonal antibody for phosphorylated-ERK (p-ERK) recognizes bands at the expected molecular weights of ERK1/2 in Western blots; antibody binding is seen only when the protein is phosphorylated (manufacturer's product information). The antibody for Arc recognizes a single band at the expected molecular weight of Arc, as documented previously (Lyford et al. 1995). The antibody for c-fos recognizes a single band at the expected molecular weight (manufacturer's product information). In addition to the evidence for specificity provided by Western blot analyses, the pattern of immunostaining for these antibodies provides strong validation for the specificity of the antibody. Antigens are distributed in the expected subcellular pattern (p-ERK in the cytoplasm and then the nucleus, Arc in dendrites and cell bodies, and c-fos in the nucleus), and staining is strikingly altered by physiological activity (see Results).

\section{Phalloidin staining}

To assess actin polymerization after induction of LTP, sections were stained with phalloidin. Sections were treated with PBS with $0.1 \%$ Triton-X-100 for $30 \mathrm{~min}$ and then blocked with $2.5 \%$ BSA and $2.5 \% \mathrm{NGS} / \mathrm{PBS}$ for $2 \mathrm{~h}$, and then incubated overnight at $4{ }^{\circ} \mathrm{C}$ with phalloidin-tetramethylrhodamine isothiocyanate (TRITC) conjugate (Sigma, $0.5 \mathrm{ug} / \mathrm{mL}$ ). After incubation, the sections were washed three times with $1 \times$ PBS and then rinsed in water once. Sections were mounted on slides and coverslipped with ProLong Gold Antifade Reagent (Invitrogen, Molecular Probes). Previous studies have confirmed that increases in phalloidin staining correspond to increases in polymerized actin (Fukazawa et al. 2003).

\section{In situ hybridization}

For in situ hybridization, floating sections were post-fixed with $4 \%$ paraformaldehyde in $0.1 \mathrm{M}$ PBS for $30 \mathrm{~min}$, then rinsed with $0.5 \times$ saline-sodium citrate buffer $(0.5 \times$ SSC, $0.1 \%$ DEPC treated $)$ for $5 \mathrm{~min}$. Sections were treated with Proteinase K $(1.25 \mathrm{mg} / \mathrm{L})$ for $15 \mathrm{~min}$, and rinsed again with $0.5 \times \mathrm{SSC}(0.1 \%$ DEPC treated $)$ for
$10 \mathrm{~min}$. The sections were incubated with $75 \mu \mathrm{L}$ of prehybridization buffer $(2 \times$ SSC, $25 \%$ formamide, $1 \%$ Denhardt's reagent, $10 \%$ dextran sulfate, $0.5 \mathrm{mg} / \mathrm{mL}$ heparin, $0.5 \mathrm{mg} / \mathrm{mL}$ yeast tRNA, and $0.25 \mathrm{mg} / \mathrm{mL}$ of denatured salmon sperm DNA) and incubated at $42^{\circ} \mathrm{C}$ for $2 \mathrm{~h}$. After the prehybridization, sections were incubated in $450 \mu \mathrm{L}$ of hybridization buffer with $2 \mu \mathrm{g}$ of DigcRNA probe for Arc mRNA (Steward et al. 1998) overnight at $55^{\circ} \mathrm{C}$. The next day, sections were washed with $2 \times \mathrm{SSC} / 10 \mathrm{mM}$ EDTA twice (10 min each). The sections were treated with RNase-A for $30 \mathrm{~min}$, and then washed twice with $2 \times$ SSC/EDTA (10 min per wash). The stringency wash was $0.5 \times$ SSC/10 m MEDTA at $55^{\circ} \mathrm{C}$ for $2 \mathrm{hr}$. After that, sections were washed with $0.5 \times$ SSC twice (10 min each at room temperature). Alkaline phosphatase conjugated antidigoxigenin Fab fragment (1:10000) was used to detect the hybridized probes. NBT/BCIP solution was applied overnight at $4^{\circ} \mathrm{C}$ to detect the alkaline phosphatase. Sections were then washed with $100 \mathrm{mM}$ Tris- $\mathrm{HCl}(\mathrm{pH} 8.5) / 1 \mathrm{mM}$ EDTA three times, $10 \mathrm{~min}$ each, and rinsed with nanopure water twice. Sections were mounted on coated slides, air dried, and covered with Kaiser's glycerol jelly.

\section{Fluorescence in situ hybridization (FISH)}

Following delivery of high-frequency stimulation, the brains were rapidly removed and quick-frozen in isopentane $\left(\sim-50^{\circ} \mathrm{C}\right)$, then stored at $-80^{\circ} \mathrm{C}$ until sectioned on a cryostat. Twentymicron-thick sections were mounted on slides, and slides were stored at $-80^{\circ} \mathrm{C}$. Digoxigenin-labeled Arc riboprobe was generated using commercial transcription kits (MaxiScript; Ambion) and digoxigenin RNA-labeling mixes (Roche Molecular Biochemicals). The plasmid used to generate the Arc antisense and sense riboprobes contained a full-length cDNA $(3.0 \mathrm{kbp})$ of the Arc transcript (Lyford et al. 1995). Fluorescence in situ hybridization for Arc was performed as described in detail elsewhere (Guzowski et al. 1999; Vazdarjanova et al. 2002). Digoxigeninlabeled Arc riboprobe was detected with antidigoxigenin-HRP (Roche Molecular) and a cyanine-3 substrate kit (CY3 DirectFISH; NEN Lifesciences). After detection of the Arc riboprobe, cell nuclei were counterstained with DAPI (Invitrogen-Molecular Probes) and then coverslipped using Vectashield (Vector Labs). The specificity of the labeling was confirmed by two control conditions. Some slides were hybridized with Arc sense riboprobes, whereas on other slides, the riboprobe was omitted. For both control conditions, the remaining detection steps were performed without modification from the standard procedure. No specific signal was detected in either of these control conditions.

\section{Acknowledgments}

Supported by NS12333 and a grant from FRAXA to O.S. and by MH060123 to J.F.G. Thanks to Kelli Sharp, Levi Maes, and Joi Nguyen for excellent technical assistance.

\section{References}

Abraham, W.C., Logan, B., Greenwood, J.M., and Dragunow, M. 2002. Induction and experience-dependent consolidation of stable long-term potentiation lasting months in the hippocampus. $J$. Neurosci. 22: 9626-9634.

Bliss, T.V.P. and Lomo, T. 1973. Long-lasting potentiation of synaptic transmission in the dentate area of the anesthetized rabbit following stimulation of the perforant path. J. Physiol. 232: 331-356.

Brakeman, P.R., Lanahan, A.A., O'Brien, R., Roche, K., Barnes, C.A., Huganir, R.L., and Worley, P.F. 1997. Homer: A protein that selectively binds metabotropic glutamate receptors. Nature 386: $284-288$.

Castren, E., Pitkanen, M., Sirvio, J., Parsadanian, A., Lindholm, D., Thoenen, H., and Riekkinen, P.J. 1993. The induction of LTP increases BDNF and NGF mRNA but decreases NT-3 mRNA in the dentate gyrus. Neuroreport 4: 895-898.

Cole, A.J., Saffen, D.W., Baraban, J.M., and Worley, P.F. 1989. Rapid increase of an immediate early gene messenger RNA in hippocampal neurons by synaptic NMDA receptor activation. Nature 340: $474-477$.

Davis, S., Vanhoutte, P., Pages, C., Caboche, J., and Laroche, S. 2000. The MAPK/ERK cascade targets both Elk-1 and cAMP response element-binding protein to control long-term

\section{Learning \& Memory}


potentiation-dependent gene expression in the dentate gyrus in vivo. J. Neurosci. 20: 4563-4572.

Desmond, N.L. and Levy, W.B. 1983. Synaptic correlates of associative potentiation and depression: An ultrastructural study in the hippocampus. Brain Res. 265: 21-30.

Desmond, N.L. and Levy, W.B. 1986. Changes in the postsynaptic density with long-term potentiation in the dentate gyrus. J. Comp. Neurol. 253: 476-482.

Desmond, N.L. and Levy, W.B. 1988. Synaptic interface surface area increases with long-term potentiation in the hippocampal dentate gyrus. Brain Res. 453: 308-314.

Douglas, R.M. 1977. Long-lasting synaptic potentiation in the rat dentate gyrus following brief high frequency stimulation. Brain Res. 126: $361-365$.

French, P.J., O'Connor, V., Jones, M.W., Davis, S., Errington, M.L., Voss, K., Truchet, B., Wotjak, C., Stean, T., Doyere, V., et al. 2001. Subfield-specific immediate early gene expression associated with hippocampal long-term potentiation in vivo. Eur. J. Neurosci. 13: $968-976$.

Fukazawa, Y., Saitoh, Y., Ozawa, F., Ohta, Y., Mizuno, K., and Inokuchi, K. 2003. Hippocampal LTP is accompanied by enhanced F-actin content within the dendritic spine that is essential for late LTP maintenance in vivo. Neuron 38: 447-460.

Guzowski, J.F., McNaughton, B.L., Barnes, C.A., and Worley, P.F. 1999. Environment-specific induction of the immediate early gene Arc in hippocampal neuronal ensembles. Nat. Neurosci. 2: 1120-1124.

Guzowski, J.F., Lyford, G.L., Stevenson, G.D., Houston, F.P., McGaugh, J.L., Worley, P.F., and Barnes, C.A. 2000. Inhibition of activity-dependent Arc protein expression in the rat hippocampus impairs the maintenance of long-term potentiation and the consolidation of long-term memory. J. Neurosci. 20: 3993-4001.

Jones, M.W., Peckham, H.M., Errington, M.L., Bliss, T.V., and Routtenberg, A. 2001a. Synaptic plasticity in the hippocampus of awake C57BL/6 and DBA/2 mice: Interstrain differences and parallels with behavior. Hippocampus 11: 391-396.

Jones, M.W., Errington, M.L., French, P.J., Fine, A., Bliss, T.V.P., Garel, S., Charnay, P., Bozon, B., Laroche, S., and Davis, S. 2001b. A requirement for the immediate early gene Zif268 in the expression of late LTP and long-term memories. Nat. Neurosci. 4: 289-296.

Kramar, E.A., Lin, B., Rex, C.S., Gall, C.M., and Lynch, G. 2006. Integrin-driven actin polymerization consolidates long-term potentiation. Proc. Natl. Acad. Sci. 103: 5579-5584.

Krug, M., Lossner, B., and Ott, T. 1984. Anisomycin blocks the late phase of long-term potentiation in the dentate gyrus of freely moving rats. Brain Res. Bull. 13: 39-42.

Lin, B., Kramar, E.A., Bi, X., Brucher, F.A., Gall, C.M., and Lynch, G. 2005. $\theta$ stimulation polymerizes actin in dendritic spines of hippocampus. J. Neurosci. 25: 2062-2069.

Lyford, G., Yamagata, K., Kaufmann, W., Barnes, C., Sanders, L.,
Copeland, N., Gilbert, D., Jenkins, N., Lanahan, A., and Worley, P. 1995. Arc, a growth factor and activity-regulated gene, encodes a novel cytoskeleton-associated protein that is enriched in neuronal dendrites. Neuron 14: 433-445.

Nguyen, P.V., Abel, T., and Kandel, E.R. 1994. Requirement of a critical period of transcription for induction of a late phase of LTP. Science 265: $1104-1107$.

Otani, S., Marshall, C.J., Tate, W.P., Goddard, G.V., and Abraham, W.C. 1989. Maintenance of long-term potentiation in rat dentate gyrus requires protein synthesis but not messenger RNA synthesis immediate post-tetanization. Neuroscience 28: 519-526.

Rosenblum, K., Futter, M., Voss, K., Erent, M., Skehel, P.A., French, P., Obosi, L., Jones, M.W., and Bliss, T.V. 2002. The role of extracellular regulated kinases I/II in late-phase long-term potentiation. $J$. Neurosci. 22: 5432-5441.

Steward, O. 1976. Topographic organization of the projections from the entorhinal area to the hippocampal formation of the rat. J. Comp. Neurol. 167: 285-314.

Steward, O. and Schuman, E.M. 2001. Protein synthesis at synaptic sites on dendrites. Annu. Rev. Neurosci. 24: 299-325.

Steward, O. and Worley, P.F. 2001. Selective targeting of newly synthesized Arc mRNA to active synapses requires NMDA receptor activation. Neuron 30: 227-240.

Steward, O., Wallace, C.S., Lyford, G.L., and Worley, P.F. 1998. Synaptic activation causes the mRNA for the immediate early gene Arc to localize selectively near activated post-synaptic sites on neuronal dendrites. Neuron 21: 741-751.

Vazdarjanova, A., McNaughton, B.L., Barnes, C.A., Worley, P.F., and Guzowski, J.F. 2002. Experience-dependent coincident expression of the effector immediate-early genes arc and Homer 1a in hippocampal and neocortical neuronal networks. J. Neurosci. 22: 10067-10071.

Wallace, C.S., Lyford, G.L., Worley, P.F., and Steward, O. 1998. Differential intracellular sorting of immediate early gene mRNAs depends on signals in the mRNA sequence. J. Neurosci. 18: 26-35.

Waltereit, R., Dammermann, B., Wulff, P., Scafidi, J., Staubli, U., Kauselmann, G., Bundman, M., and Kuhl, D. 2001. Arg3.1/Arc mRNA induction by $\mathrm{Ca}^{2+}$ and cAMP requires protein kinase $\mathrm{A}$ and mitogen-activated protein kinase/extracellular regulated kinase activation. J. Neurosci. 21: 5484-5493.

Zhang, L., Kirschstein, T., Sommersberg, B., Merkens, M., Manahan-Vaughan, D., Elgersma, Y., and Beck, H. 2005. Hippocampal synaptic metaplasticity requires inhibitory autophosphorylation of $\mathrm{Ca}^{2+} /$ calmodulin-dependent kinase II. $J$. Neurosci. 25: 7697-7707.

Received February 9, 2007; accepted in revised form April 24, 2007. 


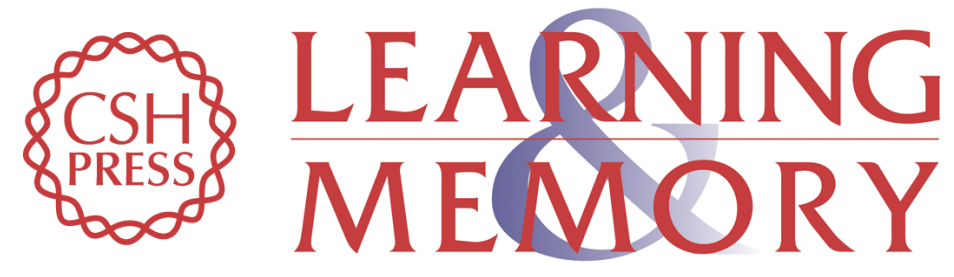

\section{A form of perforant path LTP can occur without ERK1/2 phosphorylation or immediate early gene induction}

Oswald Steward, Fen Huang and John F. Guzowski

Learn. Mem. 2007, 14:

Access the most recent version at doi:10.1101/Im.554607

References This article cites 31 articles, 11 of which can be accessed free at: http://learnmem.cshlp.org/content/14/6/433.full.html\#ref-list-1

License Freely available online through the Learning \& Memory Open Access option.

Email Alerting Receive free email alerts when new articles cite this article - sign up in the box at the Service top right corner of the article or click here. 